\title{
Study of the Aerosol Indirect Effect by Large-Eddy Simulation of Marine Stratocumulus
}

\author{
Miao-Ling Lu and John H. Seinfeld \\ California Institute of Technology, Pasadena, California
}

(Manuscript received 13 July 2004, in final form 1 February 2005)

\begin{abstract}
A total of 98 three-dimensional large-eddy simulations (LESs) of marine stratocumulus clouds covering both nighttime and daytime conditions were performed to explore the response of cloud optical depth $(\tau)$ to various aerosol number concentrations $\left(N_{a}=50-2500 \mathrm{~cm}^{-3}\right)$ and the covarying meteorological conditions (large-scale divergence rate and SST). The idealized First International Satellite Cloud Climatology Project (ISCCP) Regional Experiment (FIRE) and the Atlantic Stratocumulus Transition Experiment (ASTEX) Lagrangian 1 sounding profiles were used to represent the lightly and heavily drizzling cases, respectively. The first and second aerosol indirect effects are identified. Through statistical analysis, $\tau$ is found be to both positively correlated with $N_{a}$ and cloud liquid water path (LWP) with a higher correlation associated with LWP, which is predominantly regulated by large-scale subsidence and SST. Clouds with high LWP occur under low SST or weak large-scale subsidence. Introduction of a small amount of giant sea salt aerosol into the simulation lowers the number of cloud droplets activated, results in larger cloud droplets, and initiates precipitation for nondrizzling polluted clouds or precedes the precipitation process for drizzling clouds. However, giant sea salt aerosol is found to have a negligible effect on $\tau$ for lightly precipitating cases, while resulting in a relative reduction of $\tau$ of $3 \%-77 \%$ (increasing with $N_{a}$, for $N_{a}=$ $1000-2500 \mathrm{~cm}^{-3}$ ) for heavily precipitating cases, suggesting that the impact of giant sea salt is only important for moist and potentially convective clouds. Finally, a regression analysis of the simulations shows that the second indirect effect is more evident in clear than polluted cases. The second indirect effect is found to enhance (reduce) the overall aerosol indirect effect for heavily (lightly) drizzling clouds; that is, $\tau$ is larger (smaller) for the same relative change in $N_{a}$ than considering the Twomey (first indirect) effect alone. The aerosol indirect effect (on $\tau$ ) is lessened in the daytime afternoon conditions and is dominated by the Twomey effect; however, the effect in the early morning is close but slightly smaller than that in the nocturnal run. Diurnal variations of the aerosol indirect effect should be considered to accurately assess its magnitude.
\end{abstract}

\section{Introduction}

Particles in the atmosphere affect the radiation balance of the earth by reflecting and absorbing incoming sunlight and by acting as cloud condensation nuclei $(\mathrm{CCN})$. So-called aerosol indirect climate forcing refers to perturbation of the earth's radiation balance through modification of cloud albedo and cloud lifetime by anthropogenic aerosols. Uncertainty in the magnitude of indirect aerosol radiative forcing is large; in the 2001 Intergovernmental Panel on Climate Change (IPCC) report (Houghton et al. 2001), global aerosol indirect forcing was estimated to vary from -1.1 to -3.7

Corresponding author address: Dr. John H. Seinfeld, California Institute of Technology, MS 210-41, 1200 E. California Blvd., Pasadena, CA 91125.

E-mail: seinfeld@caltech.edu
$\mathrm{W} \mathrm{m}^{-2}$, a range comparable, but opposite in sign, to that of greenhouse gases. Whether such a large negative forcing can be consistent with firmly established greenhouse gas radiative forcing and global observed temperature rise is, in itself, a major question, but the immediate need is to understand in a detailed and specific way the microphysical mechanisms underlying the aerosol indirect effect.

The so-called first indirect, or Twomey, effect refers to the radiative impact of a decrease in cloud droplet effective radius that results from increases in aerosol number concentration, assuming a constant liquid water content (Twomey 1977). The second indirect effect refers to a decrease in precipitation efficiency and a resulting increase in cloud liquid water path and lifetime and, hence, albedo as a result the smaller droplet effective radius (Albrecht 1989). Observational evidence for the first indirect effect is substantial and is 
based on in situ measurements, for example, ship track studies (Coakley et al. 1987) or airborne observations (Brenguier et al. 2000; Heymsfield and McFarquhar 2001), satellite retrievals (Han et al. 1998; Bréon et al. 2002), and surface remote sensing measurements (Feingold et al. 2003; Kim et al. 2003; Penner et al. 2004). Observational evidence for precipitation suppression exists in biomass burning smoke (Rosenfeld 1999; Rosenfeld et al. 2002; Andreae et al. 2004; Koren et al. 2004), urban and industrial air pollution (Rosenfeld 2000), and desert dust (Rosenfeld et al. 2001).

Ultimately, prediction of the global indirect aerosol effect requires a general circulation model (GCM) with an explicit link between aerosol properties (size, number, and composition) and cloud properties. This will involve the development of appropriate aerosol-cloud parameterizations (see, e.g., Ghan et al. 1997; AbdulRazzak and Ghan 2000; Nenes and Seinfeld 2003). To unravel the intricate mechanisms by which perturbations in aerosol properties lead to perturbations in cloud properties, mechanisms that must be represented in parameterizations, it is necessary to perform individual cloud simulations at a high level of detail.

Stratocumuli have been identified as having a potentially significant impact on climate. Satellite imagery shows that marine stratiform clouds reflect much more sunlight (albedo $\sim 30 \%-40 \%$, Randall et al. 1984) than the darker underlying ocean surface (albedo $\sim 10 \%$ ) and strongly enhance the earth's global albedo. They also radiate in the longwave spectrum at approximately the same temperature as the ocean surface. Moreover, they occur with high frequency and have extensive spatial coverage with annually averaged cloud cover of approximately $34 \%$ (Warren et al. 1986). It has been estimated that the global cooling that would result from a $4 \%$ increase in the area covered by marine stratocumulus would offset the expected warming from doubling the atmospheric concentration of $\mathrm{CO}_{2}$ from the preindustrial period (Randall et al. 1984).

The responses of clouds to regional-scale variations in $\mathrm{CCN}$ are invariably subject to covarying meteorological conditions, causing the cloud microphysical response to occur together with changes from purely dynamical forcing. For example, satellite identification of the aerosol indirect effect is usually confounded by the strong dependence of cloud albedo on the cloud liquid water path (Schwartz et al. 2002). Through a six single column model (SCM) comparison study, Menon et al. (2003) found that cloud optical depth alone is not indicative of the effect of $\mathrm{CCN}$ variations because of the LWP variability associated with different meteorological conditions. Therefore, the ability to characterize the changes in LWP resulting from dynamical forcing variables, such as large-scale subsidence and sea surface temperature, and the link to the cloud optical properties, is needed. Large-eddy simulation (LES) studies of the aerosol indirect effect have generally been limited by the computation time required for 3D LES; some have employed a 2D version (e.g., Feingold et al. 1994, 1997, 1999a; Jiang et al. 2002), while others have performed 3D simulations (Feingold et al. 1999a; Ackerman et al. 2003).

The goal of the present paper is to computationally investigate the indirect effect using LES for two reasonably well-studied marine stratocumulus cases. One of the key issues that has arisen from previous studies is that purely dynamical factors may exert an effect on cloud optical depth and cloud fraction as large as or even greater than that exerted by varying microphysical properties. We therefore study the effect on cloud optical depth resulting from variations both in aerosol number concentration and key dynamical variables, as embodied by the large-scale divergence rate and the sea surface temperature. Because several previous studies have noted the particular effect of giant sea salt as a $\mathrm{CCN}$, when occurring together with pollution aerosols, we also consider the effect of giant sea salt aerosol on the cloud optical depth. The overall study is based on a series of 98 three-dimensional LES simulations. For the cases considered, we are able to generate statistical correlations between cloud optical depth, liquid water path, aerosol number concentration, subsidence rate, and sea surface temperature. The correlations are useful in quantifying the results of the LES simulations in separating dynamical effects from microphysical effects.

\section{Model setup}

\section{a. Numerical model}

In this study, we employ the three-dimensional, nonhydrostatic version of the Regional Atmospheric Modeling System (RAMS; Pielke et al. 1992; Walko et al. 1995). The predicted variables include the three velocity components, the Exner function (the pressure variable), the ice-liquid water potential temperature (Tripoli and Cotton 1981), and the total water mixing ratio. The radiation scheme is that of Chen and Cotton (1983), which parameterizes the longwave and shortwave radiative flux divergences using the mixed emissivity approach. The LES implementation uses a subgrid scheme adapted from Deardorff (1970), predicting the turbulent kinetic energy in order to evaluate eddy mixing coefficients.

The simulation uses the explicit bin-resolving warm 
cloud microphysics model (Tzivion et al. 1987, 1989; Feingold et al. 1994; Stevens et al. 1996a), which follows the moment-conserving techniques described by Tzivion et al. (1987, 1989). This microphysical model predicts for both number and mass concentration of drops in each of 36 size bins. The drop size bins are specified as mass doubling, spanning the radius size spectrum of $1.56 \mu \mathrm{m}-0.64 \mathrm{~cm}$. The microphysical processes of drop condensation/evaporation, stochastic collision/coalescence, sedimentation, and aerosol activation are considered in the simulation. The RAMS-bin microphysics model has been applied in numerical studies of Arctic boundary layer cloud from the First International Satellite Cloud Climatology Project (ISCCP) Regional Experiment (FIRE) Surface Heat Budget of the Arctic (SHEBA) (Jiang et al. 2001), the entrainment of free tropospheric aerosols into the marine boundary layer (Jiang et al. 2002), stratocumulus clouds with the FIRE or Atlantic Stratocumulus Transition Experiment (ASTEX) sounding profiles (Feingold et al. 1994; Stevens et al. 1996a, 1998), and stratocumulus coupled with the aqueous chemistry (Feingold and Kreidenweis 2002).

\section{b. Aerosol activation scheme}

\section{1) Single mode Aerosol}

In the basic droplet activation scheme implemented in the RAMS model the aerosols are assumed to have a constant size distribution in space and time; cloud droplet activation is calculated such that the number of cloud drops is based on the model-derived supersaturation but not exceeding the number concentration of aerosol. The supersaturation is prognosed in the model by the semianalytic method of solving the semiLagrangian condensation/evaporation equations derived in Tzivion et al. (1989), described in more detail by Stevens et al. (1996a). Although the Eulerian model has been known to suffer from the spurious production of cloud-top supersaturation leading to the spurious production of cloud droplets at cloud top (Stevens et al. 1996b), we have not found an immediate and practical solution for this numerical artifact. For our sensitivity studies of varying the $\mathrm{CCN}$ number concentrations, this numerical artifact does not impose a significant effect on our conclusions.

The normalized aerosol size spectrum, $f\left(a ; a_{g}, \sigma_{g}\right)$, is assumed to be lognormal,

$$
f\left(a ; a_{g}, \sigma_{g}\right)=\frac{1}{\sqrt{2 \pi} a \ln \sigma_{g}} \exp \left[-\frac{\ln ^{2}\left(a / a_{g}\right)}{2 \ln ^{2} \sigma_{g}}\right],
$$

where $a$ is the aerosol radius, and $a_{g}$ and $\sigma_{g}$ are the median radius and the geometric standard deviation of the spectrum, respectively. The characteristics of the aerosol size distribution can be varied through the parameters $a_{g}$ and $\sigma_{g}$. The number of activated drops at any time is estimated by the difference between the number of particles that would activate at the ambient supersaturation and the number of existing drops. Therefore, at each time step the drop concentration in the smallest size interval is incremented by an amount

$$
\Delta N_{c}=\max \left[0, N_{a} \int_{a_{\mathrm{cut}}}^{\infty} f\left(a ; a_{g}, \sigma_{g}\right) d a-N_{c}\right],
$$

where $N_{a}$ is the total aerosol concentration, $a_{\text {cut }}$ is the dry radius of the smallest particle activated at the ambient supersaturation $S$ (calculated by the model), and $N_{c}$ is the number concentration of cloud droplets in the previous time step. The integral in Eq. (2) is the potential fraction of activated particles, which can be obtained by integrating the lognormal size distribution (Von der Emde and Wacker 1993),

$$
\int_{a_{\mathrm{cut}}}^{\infty} f\left(a ; a_{g}, \sigma_{g}\right) d a=\frac{1}{2}[1-\operatorname{erf}(u)],
$$

where $u=\ln \left(a_{\text {cut }} / a_{g}\right) / \sqrt{2} \ln \sigma_{g}$. The activation radius $a_{\text {cut }}$ can be calculated based on the Köhler equation (Seinfeld and Pandis 1998)

$$
a_{\mathrm{cut}}=\left[\frac{4 A^{3} \rho_{w} M_{s}}{27 \nu(\ln S)^{2} \rho_{s} M_{w}}\right]^{1 / 3},
$$

where $M_{s}$ and $M_{w}$ are the molecular weight of the solute and pure water, respectively; $v$ is the number of ions the salt dissociates into (von't Hoff factor for solute in solution), $\rho_{s}$ and $\rho_{w}$ are the density of the aerosol material and water, respectively; $A$ is the coefficient of the curvature effect given by, $A=2 M_{w} \sigma_{w} / R T \rho_{w}$, where $R$ is the molar gas constant, $T$ is the temperature, and $\sigma_{w}$ is the surface tension of water. The chemical characteristics of the CCN affect $a_{\text {cut }}$.

\section{2) Multimode Aerosols}

One can extend the above single-mode aerosol activation to multiple externally mixed lognormal modes, each mode composed of a soluble material following the derivation of Abdul-Razzak and Ghan (2000). This multimode lognormal distribution is expressed as

$$
f_{i}\left(a ; a_{g, i}, \sigma_{g, i}\right)=\frac{1}{\sqrt{2 \pi} a \ln \sigma_{g, i}} \exp \left[-\frac{\ln ^{2}\left(a / a_{g, i}\right)}{2 \ln ^{2} \sigma_{g, i}}\right],
$$

where $a_{g, i}$ is the geometric mean dry radius, and $\sigma_{g, i}$ is the geometric standard deviation for each aerosol mode $i, i=1,2, \ldots, I$. 
The smallest activation size for each mode $i$ is

$$
a_{\mathrm{cut}, i}=a_{g, i}\left(\frac{S_{m, i}}{S}\right)
$$

where $S_{m, i}$ is given by

$$
S_{m, i}=\frac{2}{\sqrt{B_{i}}}\left(\frac{A}{3 a_{g, i}}\right)^{3 / 2}
$$

and the hygroscopicity parameter (solute effect) $B$ of aerosol mode $i$ can be expressed as (Pruppacher and Klett 1997)

$$
B_{i}=\frac{M_{w} q_{i} \nu_{i} \phi_{i} \epsilon_{i} / M_{s, i}}{\rho_{w} q_{i} / \rho_{s, i}}
$$

where $q_{i}$ is the mass mixing ratio of mode $i, \phi_{i}$ is the osmotic coefficient, and $\varepsilon_{i}$ is the mass fraction of soluble material. Therefore, the number of particles activated at each time step for this multimode aerosol distribution is

$$
\Delta N_{c}=\max \left[0, \sum_{i=1}^{I} N_{a, i} \int_{a_{\mathrm{cut}, i}}^{\infty} f_{i}\left(a ; a_{g, i}, \sigma_{g, i}\right) d a-N_{c}\right] .
$$

\section{LES simulation}

\section{a. Case description}

We consider the intercomparison model study of a stratocumulus-topped planetary boundary layer of the Global Energy and Water Cycle Experiment (GEWEX) Cloud System Study (GCSS) boundary layer cloud Working Group 1 (Moeng et al. 1996). The sounding profile is loosely based on the FIRE of the 7 July 1987 horizontally homogeneous and nearly solid cloud deck reported in Betts and Boers (1990). The simulation is an idealized nighttime stratocumulustopped marine boundary layer (MBL) case, and there is little wind shear and surface heating. The cloudy MBL is driven mainly by cloud-top IR cooling and modified by entrainment and condensation/evaporation processes. This sounding profile and configuration have been used in several previous studies, for example, Feingold et al. (1994, 1996) and Stevens et al. (1996a).

The model was set up with sea surface temperature as $288 \mathrm{~K}$. The large-scale subsidence is prescribed by $w_{\text {sub }}=-D z$, where the large-scale divergence $D=5 \times$ $10^{-6} \mathrm{~s}^{-1}$. The subsidence velocity $\left(w_{\text {sub }}\right)$ is applied to the scalar tendency terms similar to Krueger (1988). The roughness length is $0.0002 \mathrm{~m}$. The initial wind field was set to equal to the geostrophic wind, set to be
$2 \mathrm{~m} \mathrm{~s}^{-1}$ in the $x$ direction and $-4 \mathrm{~m} \mathrm{~s}^{-1}$ in the $y$ direction. The initial sounding profile of potential temperature $\theta$ and total liquid water mixing ratio $\left(q_{T}, q_{T}=q_{v}+\right.$ $q_{l}$, where subscripts $v$ and $l$ represent vapor and liquid, respectively) are given in Fig. 1. Only longwave radiation is considered for this nocturnal case. The radiative cooling rate is updated every $10 \mathrm{~s}$ in the simulation. The grid resolution is $55 \mathrm{~m}$ in $x$ and $y$ and $25 \mathrm{~m}$ in $z$. The numerical time step used is $2 \mathrm{~s}$. White noise with amplitude of $0.1 \mathrm{~K}$ was applied on the temperature field at the lowest level. To accommodate the 98 threedimensional simulations (Table 1 ), we reduced the computation domain down to $1.1 \mathrm{~km} \times 1.1 \mathrm{~km}$ in the horizontal. We had chosen the BASE case (described subsequently) to validate the use of the smaller domain against the $3.3 \mathrm{~km} \times 3.3 \mathrm{~km}$ domain (BASELG) used in Moeng et al. (1996). Figure 2 demonstrates that the trend of simulated domain-averaged cloud optical depth (and also cloud albedo, not shown) versus aerosol number concentration is similar for both domain sizes, and the differences of actual values are small. The difference between the small domain results over the large domain results, averaged over the six CCNs, is $5.2 \%$, slightly smaller than the averaged data standard deviation (i.e., the error bar in the figure). Since our purpose is to investigate the relative change of the spatially and temporally averaged variables due to other external parameters, for example, SST, Fig. 2 suggests that the use of the smaller domain is sufficient for our purpose. We return to Fig. 2 subsequently to discuss the effect of varying $N_{a}$. The vertical domain is $1.2 \mathrm{~km}$, the same as that used in Moeng et al. (1996). Each simulation was run for six hours and requires about two hours to establish a well-mixed stratocumulus and resolvedscale boundary layer turbulence. Therefore, predictions for the final three hours are used in evaluating the FIRE simulations.

A constant background completely soluble ammonium sulfate aerosol with lognormal distribution mean radius $a_{g}=0.0695 \mu \mathrm{m}$ and $\sigma_{g}=2.03$ (d'Almeida et al. $1991)$ is used. The aerosol density is $1.77 \mathrm{~g} \mathrm{~m}^{-3}$, the aerosol molecular weight is $132.14 \mathrm{~g} \mathrm{~mol}^{-1}$ (AbdulRazzak et al. 1998), and we assume complete dissociation $\nu=3$. The aerosol number concentration, $N_{a}$, is set at six different levels, 50, 100, 500, 1000, 1500, and 2000 $\mathrm{cm}^{-3}$, to represent increasing anthropogenic pollution loadings. The above configurations are considered to be the base run (referred to as BASE, hereafter). Aerosol number concentrations of $N_{a}=50$ and $100 \mathrm{~cm}^{-3}$ are referred to as "clean" cases and those with $N_{a} \geq 500$ $\mathrm{cm}^{-3}$ are referred to as "polluted" cases. We do not, in this study, consider aerosol chemical effects on cloud 

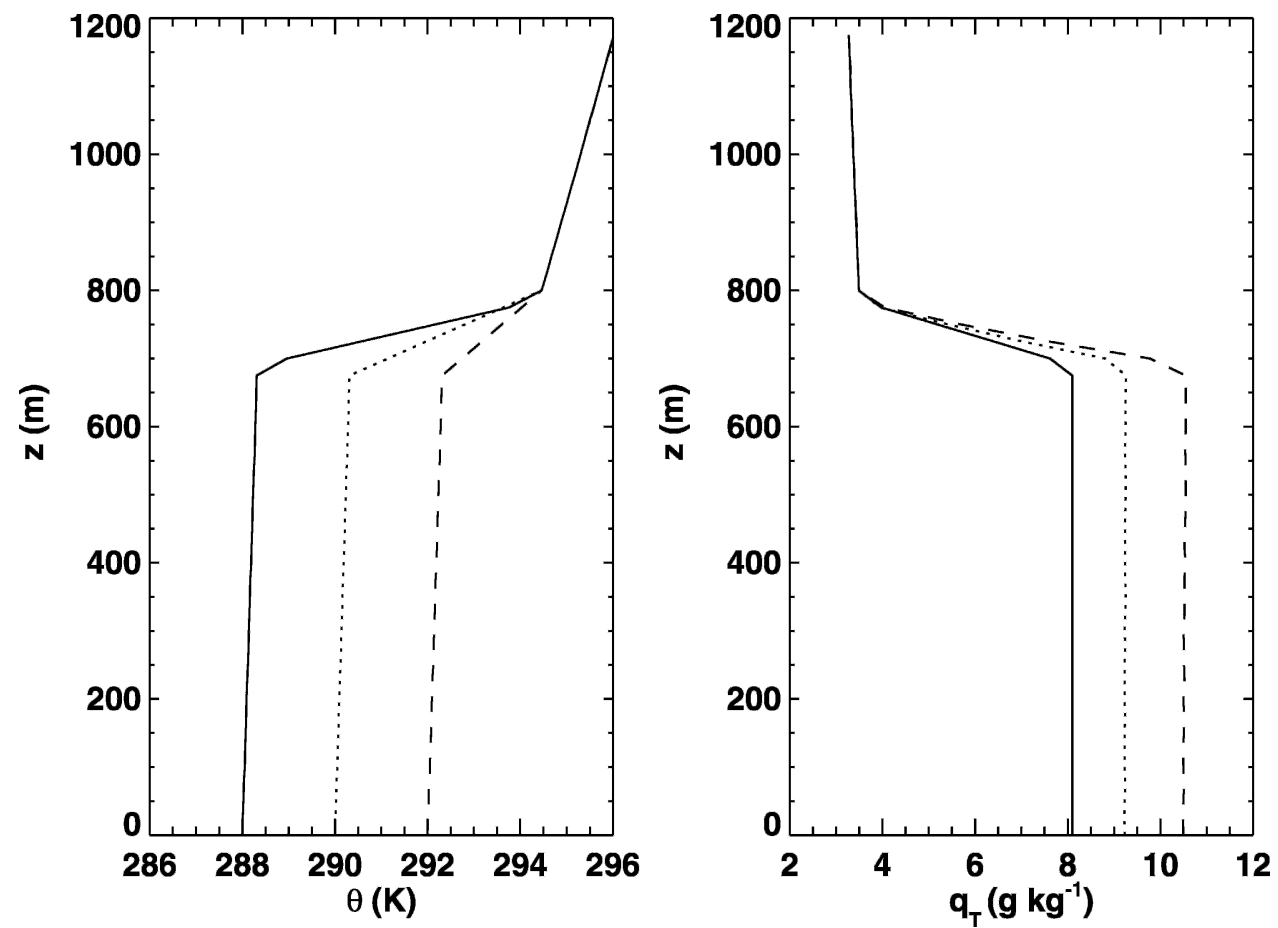

FIG. 1. Initial sounding profile for a lightly drizzling stratocumulus cloud. Solid line is for BASE run (data from Moeng et al. 1996), dotted line is for SST2 run, and dashed line is for SST4 run.

droplet activation. Such effects have been addressed in the context of adiabatic parcel models (Nenes et al. 2002).

\section{b. Meteorological conditions}

Stratocumulus clouds generally lie to the east of the subtropical high pressure and their cloud depths, cloudiness, and marine boundary layer circulations are closely related to the meteorological conditions (e.g., Schubert et al. 1979a,b; Wakefield and Schubert 1981; Krueger et al. 1995; Wyant et al. 1997). The numerical study of a cloud-topped mixed-layer model by Schubert et al. (1979b) showed that the adjustment time under the downstream varying meteorological conditions for steady-state solution of cloud top is long (several days, especially for adjustment to large-scale divergence). The computation utilizing LES for Lagrangian numerical simulations of the subtropical marine boundary layer over the possible range of values of SST and large-scale divergence is inevitably too extensive. Therefore, we perform several sensitivity experiments by slightly varying the cloud LWP through initially changing the SST and large-scale divergence.

We consider two cases-SST2 (2 K warmer than the base run) and SST4 (302 K) in addition to the base run $(288 \mathrm{~K})$ - to study the effect of warmer SST. The initial boundary layer $\theta$ is adjusted in each case to be the constant value of the warmer SST, while the free tropospheric temperature remains the same as in BASE (Fig. 1). Meanwhile, the initial profile of $q_{T}$ should also be adjusted to the corresponding increase of SST. The climatological RH of the atmospheric boundary layer over tropical (trade wind or ITCZ) oceans has been observed to remain in a narrow range around $80 \%$ (Fitzjarrald and Garstang 1981). The vertical profile of $q_{T}$ is adjusted to be the same $\mathrm{RH}$ value as that in the BASE run, and the $q_{T}$ profile in the free troposphere is the same as in the BASE run.

The large-scale divergence rate is not readily obtainable through regular observation; one tends to rely on values derived from numerical weather prediction models like the National Centers for Environmental Prediction (NCEP) and the European Centre for MediumRange Weather Forecasts (ECMWF). A large-scale divergence rate of $4.0 \times 10^{-6} \mathrm{~s}^{-1}$ was measured in ASTEX with $20 \%$ uncertainty (Ciesielski et al. 1999). The value of the rate used in stratocumulus simulations typically lies in the range of $3-5 \times 10^{-6} \mathrm{~s}^{-1}$ (Wakefield and Schubert 1981; Moeng et al. 1996; Wyant et al. 1997); however, a value exceeding $10 \times 10^{-6} \mathrm{~s}^{-1}$ was used for the European cloud model intercomparison in order to obtain a realistic cloud-top height evolution (Duynkerke et al. 1999; Chlond and Wolkau 2000). The base value of divergence rate (Table 1) is chosen here 
TABLE 1. Conditions of simulations.

\begin{tabular}{|c|c|c|c|c|c|c|c|}
\hline Expt & $N_{a}\left(\mathrm{~cm}^{-3}\right)$ & $\begin{array}{l}\text { Domain }^{\mathrm{a}} \\
\quad(\mathrm{km})\end{array}$ & $D\left(\mathrm{~s}^{-1}\right)$ & $\begin{array}{l}\text { SST } \\
(\mathrm{K})\end{array}$ & Aerosol composition & $\begin{array}{l}\text { Night/daytime } \\
\text { cloud }\end{array}$ & Sounding \\
\hline BASE & $50,100,500,1000,1500,2000$ & 1.1 & $5 \times 10^{-6}$ & 288 & Sulfate & night & Fig. 1 \\
\hline DIV2 & $50,100,500,1000,1500,2000$ & 1.1 & $2 \times 10^{-6}$ & 288 & Sulfate & night & Fig. 1 \\
\hline DIV6 & $50,100,500,1000,1500,2000$ & 1.1 & $6 \times 10^{-6}$ & 288 & Sulfate & night & Fig. 1 \\
\hline DIV10 & $50,100,500,1000,1500,2000$ & 1.1 & $10 \times 10^{-6}$ & 288 & Sulfate & night & Fig. 1 \\
\hline SST2 & $50,100,500,1000,1500,2000$ & 1.1 & $5 \times 10^{-6}$ & 290 & Sulfate & night & Fig. 1 \\
\hline SST4 & $50,100,500,1000,1500,2000$ & 1.1 & $5 \times 10^{-6}$ & 292 & Sulfate & night & Fig. 1 \\
\hline UGSALT & $50,100,500,1000,1500,2000$ & 1.1 & $5 \times 10^{-6}$ & 288 & $\begin{array}{l}\text { Sulfate and giant and } \\
\text { ultragiant drop } \\
\text { modes sea salt }\end{array}$ & night & Fig. 1 \\
\hline BASESW & $50,100,500,1000,1500,2000$ & 1.1 & $5 \times 10^{-6}$ & 288 & Sulfate & day & Fig. 1 \\
\hline BASELG & $50,100,500,1000,1500,2000$ & 3.3 & $5 \times 10^{-6}$ & 288 & Sulfate & night & Fig. 1 \\
\hline SST4LG & $50,100,500,1000,1500,2000$ & 3.3 & $5 \times 10^{-6}$ & 292 & Sulfate & night & Fig. 1 \\
\hline BASEH & $\begin{array}{l}50,100,500,1000,1500,2000, \\
\quad 2500\end{array}$ & 3.3 & $5 \times 10^{-6}$ & 290.4 & Sulfate & night & Fig. 12 \\
\hline BASEHSM & $\begin{array}{l}50,100,500,1000,1500,2000, \\
\quad 2500\end{array}$ & 1.1 & $5 \times 10^{-6}$ & 290.4 & Sulfate & night & Fig. 12 \\
\hline UGSALTH & $1000,1500,2000,2500$ & 3.3 & $5 \times 10^{-6}$ & 290.4 & $\begin{array}{l}\text { Sulfate and giant and } \\
\text { ultragiant drop } \\
\text { modes sea salt }\end{array}$ & night & Fig. 12 \\
\hline UGSALTHV10 & 1500,2000 & 3.3 & $5 \times 10^{-6}$ & 290.4 & $\begin{array}{l}\text { Sulfate and giant and } \\
\text { ultragiant drop } \\
\text { modes sea salt } \mathrm{t}^{\mathrm{b}}\end{array}$ & night & Fig. 12 \\
\hline GSALTH & $1500,2000,2500$ & 3.3 & $5 \times 10^{-6}$ & 290.4 & $\begin{array}{l}\text { Sulfate and giant drop } \\
\text { mode sea salt }\end{array}$ & night & Fig. 12 \\
\hline WASHOUTH & $50,100,2000$ & 3.3 & $5 \times 10^{-6}$ & 290.4 & $\begin{array}{l}\text { Sulfate with aerosol } \\
\text { washout mechanism }\end{array}$ & night & Fig. 12 \\
\hline BASEHSW & $\begin{array}{l}50,100,500,1000,1500,2000, \\
2500\end{array}$ & 3.3 & $5 \times 10^{-6}$ & 290.4 & Sulfate & day & Fig. 12 \\
\hline BASEHDIU & $50,100,500,1500,2500$ & 3.3 & $5 \times 10^{-6}$ & 290.4 & Sulfate & diurnal $^{\mathrm{c}}$ & Fig. 12 \\
\hline
\end{tabular}

${ }^{\text {a }}$ Domain size is the same in both $x$ and $y$ directions.

${ }^{\mathrm{b}}$ Sea salt number concentration is calculated at the sounding profile of $v=10 \mathrm{~m} \mathrm{~s}^{-1}$.

${ }^{\mathrm{c}}$ For local standard time from 2300 to 1600.

as $5 \times 10^{-6} \mathrm{~s}^{-1}$. Other values used are $2 \times 10^{-6} \mathrm{~s}^{-1}$ (DIV2), $6 \times 10^{-6} \mathrm{~s}^{-1}$ (DIV6), and $10 \times 10^{-6} \mathrm{~s}^{-1}$ (DIV10).

\section{Results}

\section{a. Liquid water path}

Averaged cloud LWP as a function of aerosol number concentration for various values of divergence rate and SST is shown in Fig. 3. Simulation results presented in this figure are temporally averaged over the final three hours and spatially over the cloudy region within the domain. Cloud LWP is calculated by the integration of the liquid water content (LWC) over the depth of the cloud,

$$
\mathrm{LWP}=\int_{z_{b}}^{z_{t}} \operatorname{LWC}(z) d z=\int_{z_{b}}^{z_{t}} \int_{r_{l}}^{r_{u}} \frac{4}{3} \pi \rho_{w} r^{3} n(r) d r d z
$$

where $z_{b}$ is cloud base and $z_{t}$ is cloud top; $r_{l}$ and $r_{u}$ are the lower and upper radius of the hydrometeor number distribution, $n(r)$, respectively.

Cloud LWP varies only slightly with aerosol concentration, particularly at high aerosol loadings. There is a slight decrease of LWP as $N_{a}$ increases from 50 to 500 $\mathrm{cm}^{-3}$ in each of the cases. The effect of high pollution loadings in suppressing drizzle formation (Albrecht 1989) is evidenced as precipitation disappears when $N_{a}$ exceeds $500 \mathrm{~cm}^{-3}$ (Fig. 4c). Also, the cloud droplet effective radius (averaged over the upper one-third of the cloud depth; Fig. 4b), $r_{e}=\int_{r_{l}}^{r_{u}} r^{3} n(r) d r / \int_{r_{l}}^{r_{u}} r^{2} n(r) d r$ (a measure of the droplet size that contributes most strongly to the radiance, Hansen and Travis 1974), for $N_{a}=50$ and $100 \mathrm{~cm}^{-3}$ is larger than the $15-\mu \mathrm{m}$ mean cloud droplet diameter (equivalent to an effective radius of about $8.5 \mu \mathrm{m}$ ) generally considered to be required for the onset of precipitation (Yum and Hudson 2002). However, the precipitation is weak for the FIRE case. Vertical profile of the sedimentation flux (Fig. 5; 


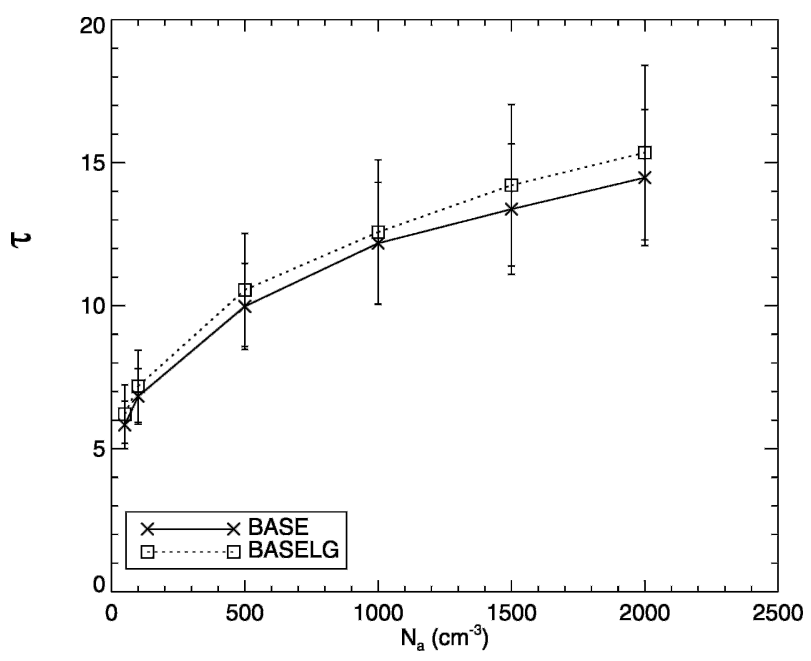

FIG. 2. Effect of region size on averaged cloud optical depth as a function of aerosol number concentration. BASE run (solid line) performed over a horizontal region of $1.1 \mathrm{~km} \times 1.1 \mathrm{~km}$, while the same configuration but a domain of $3.3 \mathrm{~km} \times 3.3 \mathrm{~km}$ (BASELG) is shown as the dotted line. The average is performed over the horizontal domain during the final $3 \mathrm{~h}$ of the simulation. Error bars represent the standard deviation of the domainaveraged values.

$F_{\text {sed }}=\rho_{0} L \int_{r_{l}}^{r_{u}} v_{t}(r) q_{l}(r) d r$, where $v_{t}$ is the droplet terminal velocity, $L=2.5 \times 10^{6} \mathrm{~J} \mathrm{~kg}^{-1}$, and $\rho_{0}$ is the air density.) shows a similar trend with that of LWC-they both peak at the same height, and the sedimentation flux drops quickly close to zero below the cloud base. Therefore, sedimentation flux is not dominated by the drizzle drops and very little surface precipitation is pro-

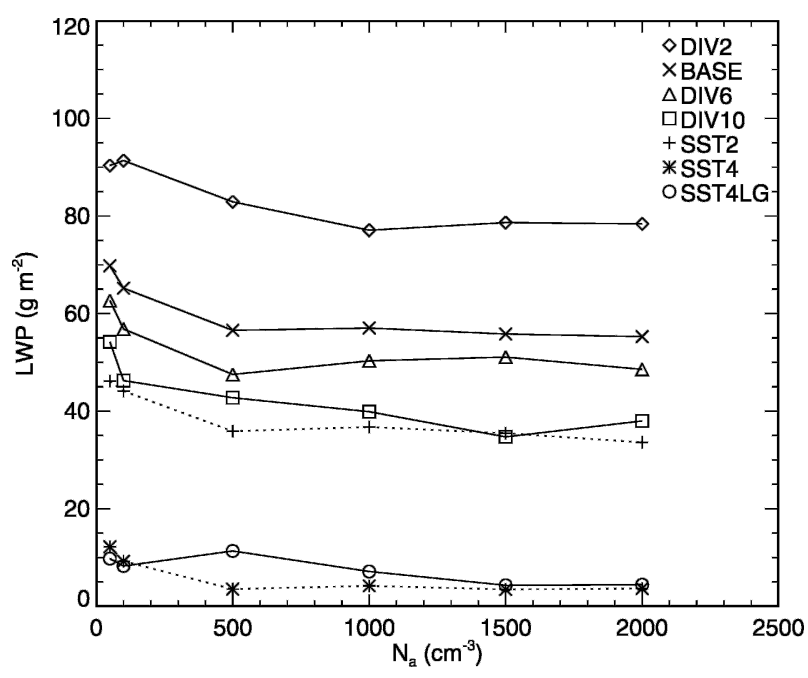

FIG. 3. Cloud LWP for seven simulations defined in Table 1. Data points are averages over the horizontal domain during the final $3 \mathrm{~h}$ of the simulation. duced (Fig. 4c). This trend of the higher LWP for smaller $N_{a}$ could be due to the weak precipitation effect on the stratocumulus-topped MBL dynamics. The study of the detailed dynamical responses of strong precipitation for the stratocumulus by Stevens et al. (1998) concluded that the cloud-top entrainment rate and the boundary layer turbulence are decreased due to precipitation and they further hypothesized that light drizzle might lessen the cloud-top entrainment drying and result in a deeper boundary layer. Ground-based observations during the ASTEX (Feingold et al. 1999b) also showed that drizzling cases were characterized by smaller in-cloud turbulence than the nondrizzling cases. Figure $6 \mathrm{a}$ is the vertical profile of the resolved-scale $\overline{w^{\prime} w^{\prime}}$ (Fig. 6a) for one case each of the clean drizzling clouds $\left(N_{a}=50 \mathrm{~cm}^{-3}\right)$ and nondrizzling clouds $\left(N_{a}=\right.$ $2000 \mathrm{~cm}^{-3}$ ), respectively. Also, $\overline{w^{\prime} w^{\prime}}$ is the horizontally averaged vertical velocity variance, which is a measure of the turbulence activity. It shows that boundary turbulent motion is weaker for the drizzling cloud than the nondrizzling cloud, in agreement with previously mentioned studies. Therefore the result shows that drizzle formation in the cloud releases latent heat, which partially compensates for the cloud-top longwave cooling, stabilizes the subcloud atmosphere by evaporation, lessens the boundary layer turbulence, and reduces the cloud-top entrainment drying. We calculate the entrainment rate, $E$, based on the mixed-layer model, such that $E=d h / d t+D h$ where $h$ is the temperature inversion base, which can be approximated by the horizontal mean cloud top (Moeng et al. 1999). From the above equation, $E=0.64$ and $0.66 \mathrm{~cm} \mathrm{~s}^{-1}$ (averaged over the last five hours) for $N_{a}=50 \mathrm{~cm}^{-3}$ and $N_{a}=$ $2000 \mathrm{~cm}^{-3}$, respectively. Therefore, the simulation shows a small reduction of cloud-top entrainment drying effect for the clean clouds. Meanwhile, the evaporation of those drizzle fall below the cloud base can moisten and cool the subcloud layer as shown in Figs. $6 \mathrm{~b}$ and $6 \mathrm{c}$. It follows that the cloud lifting condensation level lowers. Considering these two dynamical responses, the result shows cloud LWP is slightly higher for the clean clouds (Fig. 6d) in contrast to the typical secondary aerosol effect (e.g., Albrecht 1989). This decreasing LWP with increasing pollution level is not limited to our simulation.

Brenguier et al. (2003), through the second North Atlantic Regional Aerosol Characterization Experiment (ACE-2) measurements over the Atlantic, found that polluted clouds tended to be thinner than clean clouds. Twohy et al. (2005) found a weak anticorrelation between cloud geometrical thickness/cloud LWP and particle concentration from three of the four clean- 

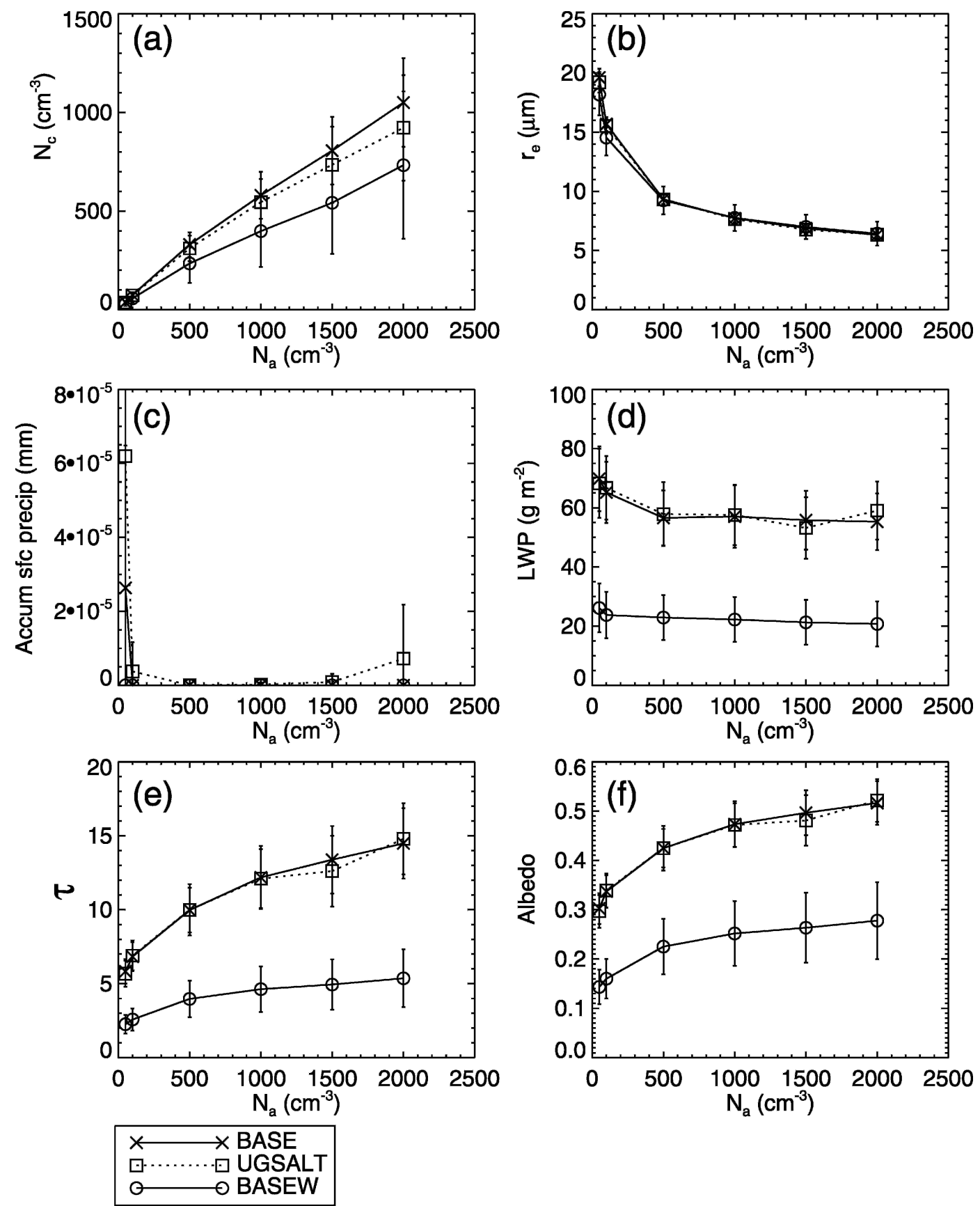

FIG. 4. Supermicron sea salt effect (see section 5 for details) for weakly precipitating stratocumulus cloud (a) $N_{c}$, (b) $r_{e}$, (c) accumulated surface precipitation, (d) cloud LWP, (e) $\tau$, and (f) cloud albedo for BASE, UGSALT, and BASESW. The accumulated surface precipitation is summed over the 6-h simulations.

est cloud cases from Dynamics and Chemistry of Marine Stratocumulus-II (DYCOMS-II), an airborne measurement of stratocumulus clouds over the eastern $\mathrm{Pa}-$ cific Ocean off the coast of San Diego, California. These in situ aircraft field measurements also support our simulation results of a weak decreasing LWP with increasing aerosol number.
As the large-scale divergence rate increases (DIV2, BASE, DIV6, and DIV10), the cloud top is slowly driven down, thinning the cloud depth, and therefore cloud LWP decreases (Fig. 3). Cloud LWP decreases with increasing SST. The fractional cloudiness, averaged over the final three hours and over six $N_{a}$ cases, for BASE and SST2 are both approximately 1, but it 


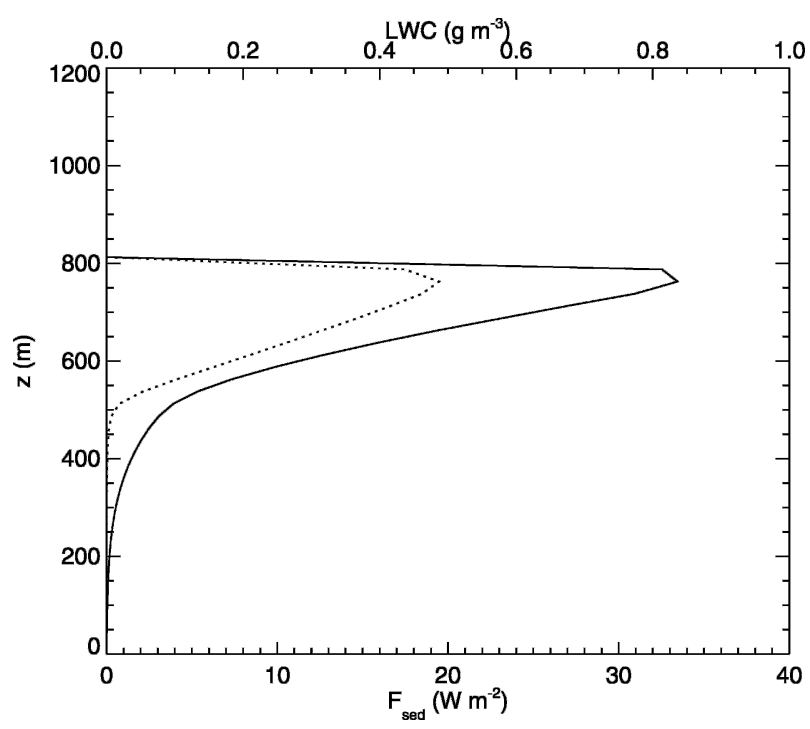

FIG. 5. Vertical profiles of sedimentation flux (solid line, lower axis) and LWC (dotted line, upper axis) for BASE $N_{a}=50 \mathrm{~cm}^{-3}$, horizontally averaged over the final $3 \mathrm{~h}$ of the simulation.

decreases to roughly 0.4 for SST4. This behavior is similar to the stratocumulus to trade cumulus transition when air advects from the subtropical regime over warmer ocean (Albrecht et al. 1995; Wyant et al. 1997). Conditions become less cloudy because of gradual dissipation of the overlying stratocumulus clouds. Results in Fig. 7 at simulation $t=6 \mathrm{~h}$ show that cloud-base (-top) height increases from $507 \mathrm{~m}$ (812 m) for BASE to $641 \mathrm{~m}(836 \mathrm{~m})$ for SST4. This behavior agrees with both observations and simulations (e.g., Schubert et al. 1979a; Krueger et al. 1995; Wyant et al. 1997) that the stratocumulus-topped boundary layer deepens and cloud base rises with warmer SST. Longwave cooling at the cloud top drives the turbulent mixing through the entire boundary layer and maintains the layer in a wellmixed state. In the SST4 simulation (Fig. 7c), the initially broken cloud progressively forms a homogeneous solid deck due to longwave radiative cooling of the cloud top, gradually producing a well-mixed boundary layer.

Because of the fracture cloud fields seen in the early hours of SST4, we also carry out the same simulation but in the larger $3.3 \mathrm{~km} \times 3.3 \mathrm{~km}$ horizontal domain (SST4LG). Results show that cloudiness for clean clouds of SST4LG are about 0.4 smaller than 0.7 of SST4, but they are comparable for polluted clouds. The averaged LWP and cloud optical depth (see next paragraph) and their trends with $N_{a}$ of SST4LG are roughly close to those of SST4 (Figs. 3 and 8), suggesting the use of LWP and cloud optical depth of SST4 for subsequent analysis is appropriate.

\section{b. Cloud optical depth}

Cloud optical depth is determined by

$$
\tau=\int_{z_{b}}^{z_{t}} \int_{r_{l}}^{r_{u}} 2 \pi r^{2} n(r) d r d z,
$$

where the extinction efficiency approaches asymptotically a value of 2 for cloud droplets at visible wavelength (Seinfeld and Pandis 1998). Figure 8 shows that cloud optical depth increases with increasing aerosol burden. The trend of cloud optical depth versus aerosol number concentration is very similar to that of $\tau$ versus $N_{a}$ (Fig. 4f), where the cloud albedo is calculated in each column by albedo $=(1-g) \tau /[2+(1-g)] \tau$ (Bohren 1980), and $g$ is the asymmetry factor $(\approx 0.85)$. Because the averaged cloud optical depth is more sensitive to the aerosol number concentration than is LWP (Fig. 3), change of cloud optical depth with $N_{a}$, the Twomey effect, is clearly evident for all simulations except for SST4 in which the LWP itself is small.

To examine the relationship between $\tau$ and LWP, we replot each data point in Figs. 3 and 8 in $\tau$-LWP (Fig. 9). Low LWP, and hence thinner cloud, is on the lefthand side of Fig. 9 corresponding to higher SST or stronger divergence, while high LWP and thicker cloud conditions are on the right-hand side, corresponding to lower SST or weaker large-scale subsidence. Cloud optical depth is highly positively correlated with LWP. This is consistent with satellite measurements of strong dependence of cloud albedo on LWP (Schwartz et al. 2002). Cloud optical depth is dependent on both LWP (or $H$ ) and $N_{a}$ as corroborated observationally (Brenguier et al. 2000). For the same cloud optical depth, a clean cloud has higher $H$ than a polluted cloud, as also seen in aircraft in situ measurements of clouds [i.e., Fig. 2 of Brenguier et al. (2000) at constant $\tau$ line]. Figure 9 also illustrates that the Twomey effect as seen by comparing $\tau$ for polluted and clean clouds at constant LWP. The change of cloud optical depth per increase of cloud droplet number concentration (i.e., $d \tau / d \ln N_{c}$ at constant LWP) is larger for thicker cloud; in the present simulations, they are a solid stratocumulus deck with lower SST or lower divergence.

We also overlay the figure with the constant $r_{e}$ lines, derived from Stephens (1978) based on a spatially uniform cloud with monodisperse cloud droplets,

$$
r_{e}=1.5 \mathrm{LWP} / \tau \text {. }
$$

The simulated $r_{e}$ is averaged over the upper one-third of the cloud because the cloud radiative properties are mainly determined from their values near the cloud top. The simulated $r_{e}$ in general is close to the theoretical lines, but the large deviation appears for SST4 due 

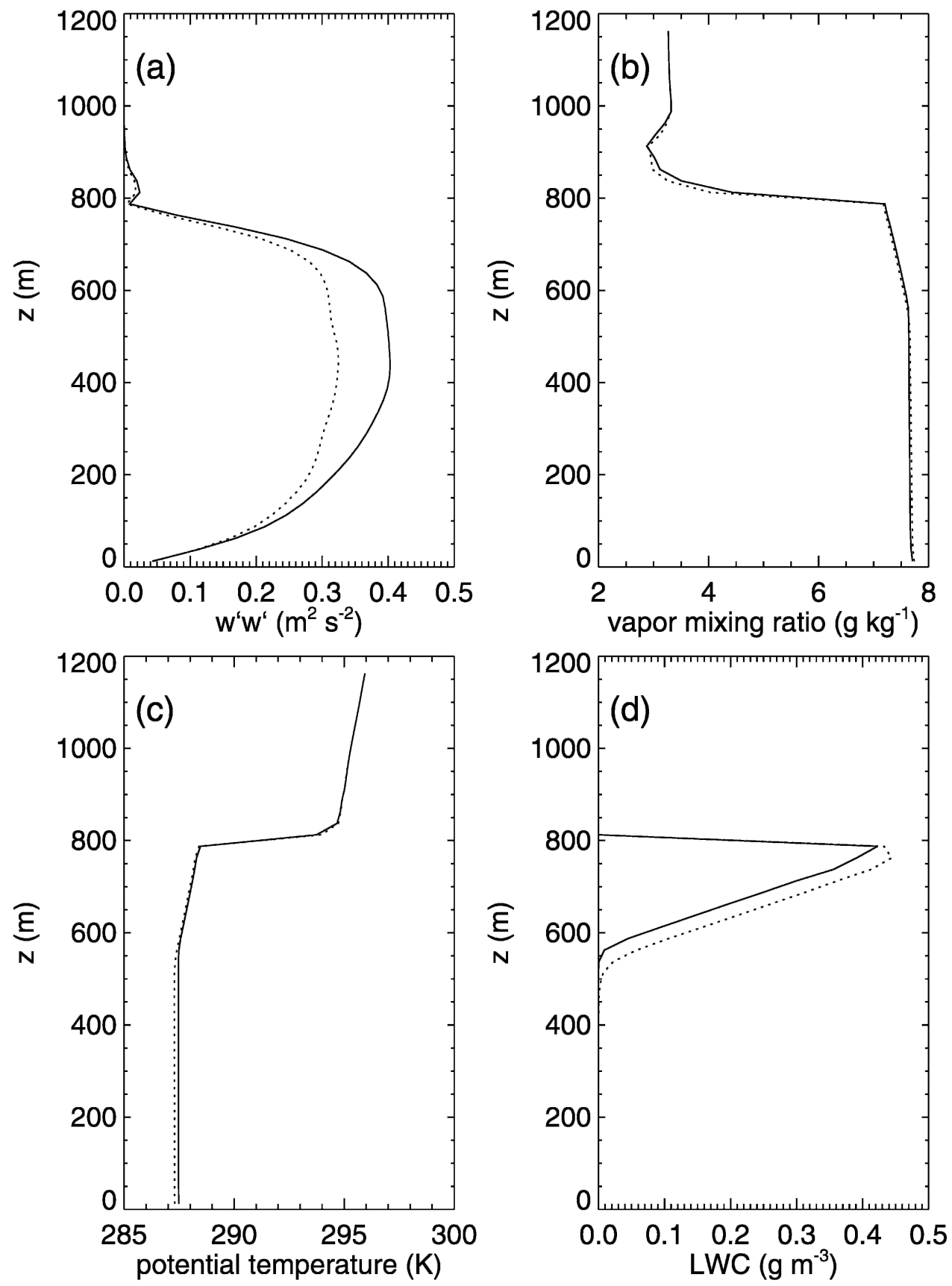

FIG. 6. Vertical profiles of the temporally (last $3 \mathrm{~h}$ ) and horizontally averaged (a) vertical velocity variance, (b) water vapor mixing ratio, (c) potential temperature, and (d) cloud LWC. Solid line represents the nondrizzling cloud (BASE, $N_{a}=2000 \mathrm{~cm}^{-3}$ ) and the dotted line represents the drizzling cloud (BASE, $N_{a}=50 \mathrm{~cm}^{-3}$ ).

to spatially inhomogeneous cloud morphology for this experiment. It can be identified clearly from the figure that the data points can be grouped into polluted and clean cases based on $r_{e}$. The slopes (i.e., 0.27 and 0.13) are inversely proportional to the $r_{e}$, which is also explained by Eq. (11).
A multiple regression of cloud optical depth as a function of $N_{a}$ and LWP data points, horizontal averages sampled every $5 \mathrm{~min}$ during the final $3 \mathrm{~h}$ for the six weakly drizzling nocturnal experiments (the first six experiments in Table 1, hereafter LIGHTDALL), yields 

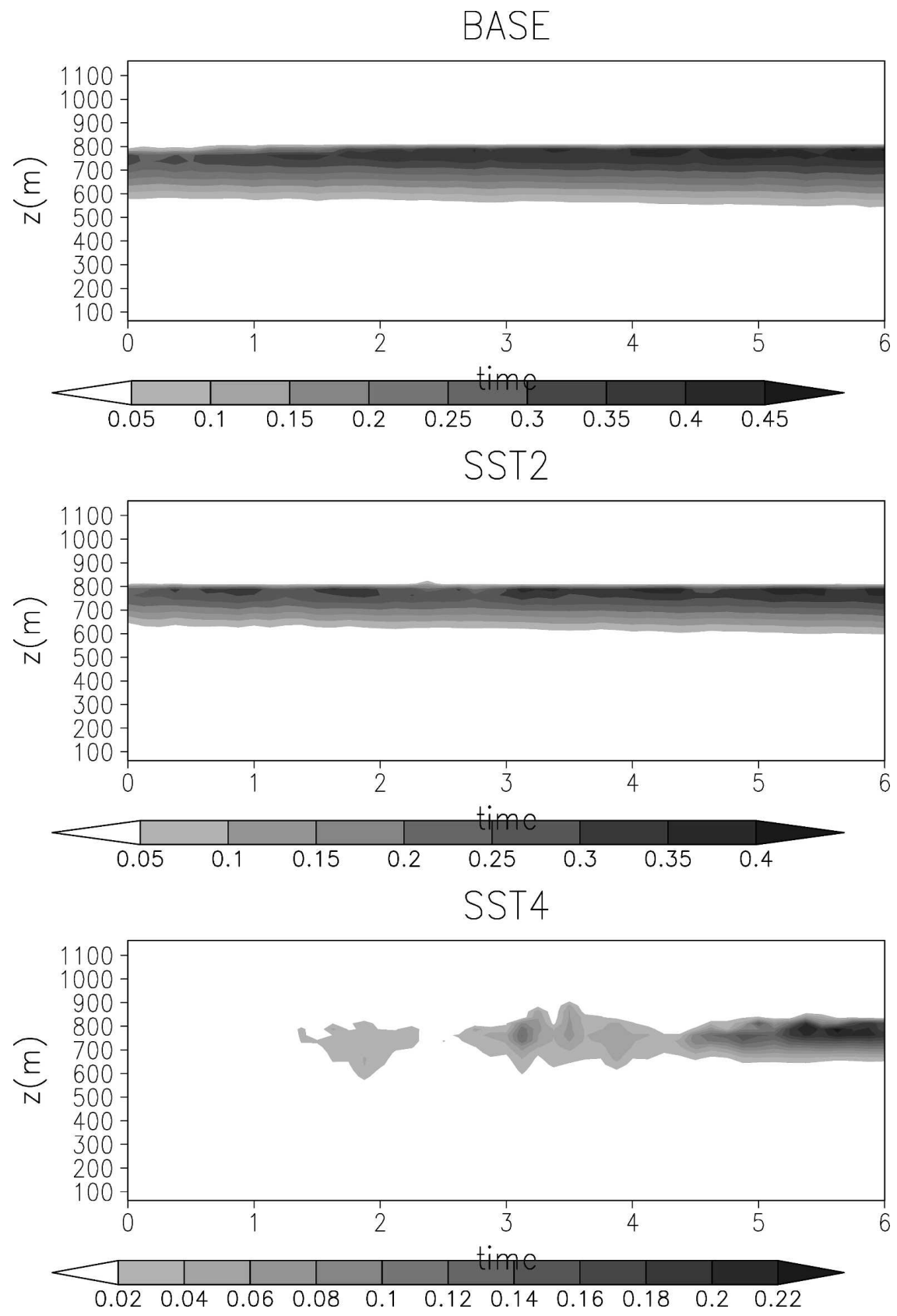

FIG. 7. Temporal evolution of horizontally averaged cloud mixing ratio $\left(\mathrm{g} \mathrm{kg}^{-1}\right)$ for (a) BASE, (b) SST2, and (c) SST4. Aerosol number concentration is $50 \mathrm{~cm}^{-3}$.

$$
\begin{aligned}
& \ln \tau=0.31 \ln N_{a}+0.93 \ln \mathrm{LWP}-3.39 \\
& R^{2}=1.0=(1208 \text { data points }) .
\end{aligned}
$$

The partial correlation coefficients of $\tau$ versus $N_{a}$ and LWP are 0.58 and 0.75 , respectively. The regression result suggests that $\tau$ is more sensitive to LWP variation than to $N_{a}$. The relationship between cloud droplet number concentration $N_{c}$ and $N_{a}$ at constant LWP can be expressed empirically as

$$
N_{c}=1.09 N_{a}^{0.91} \quad(1100 \text { data points })
$$

The above equation is obtained by the averaged regression results of $N_{c}-N_{a}$ at every binned LWP with LWP bin size of $5 \mathrm{~g} \mathrm{~m}^{-2}$ with a 5-min sampling frequency 


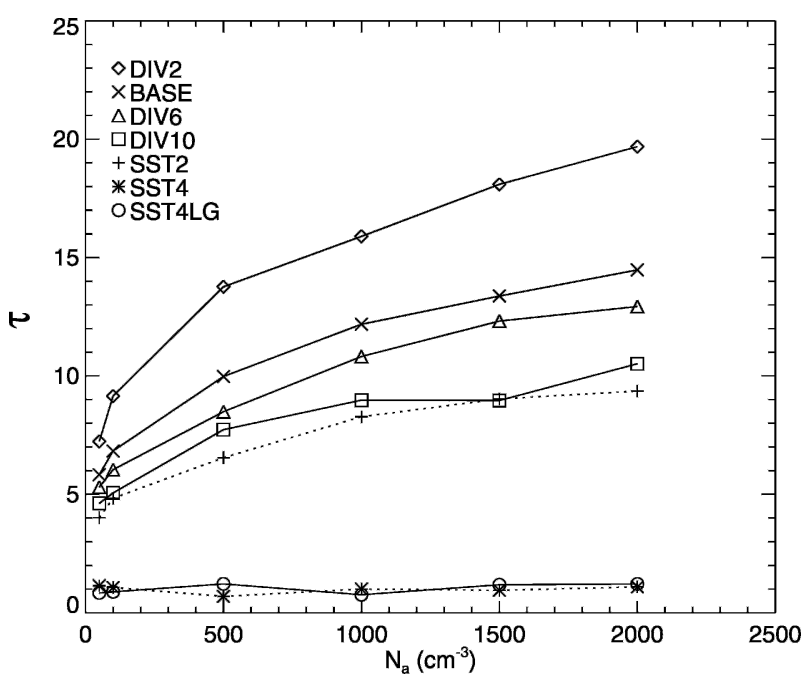

FIG. 8. Cloud optical depth for seven simulations defined in Table 1. Data points are averages over the horizontal domain during the final $3 \mathrm{~h}$ of the simulation.

during the final $3 \mathrm{~h}$ (for LWP $\geq 25 \mathrm{~g} \mathrm{~m}^{-2}$; Fig. 10). This figure also shows that our simulations agree well with the nocturnal measurement results from DYCOMS-II (Twohy et al. 2005). Using the result of Eq. (13), Eq. (12) can be expressed as

$$
\tau \propto N_{c}^{0.34}
$$

for constant LWP. Interestingly, the result is the same as that from a homogeneous cloud of a constant LWC. However, Eq. (14) is the statistical product comprising the interactions of diabatic effects of radiation, precipitation, and entrainment, as well as cloud inhomogeneity.

In summary, Eq. (12) shows that cloud optical depth $\tau$ is more sensitive to the dynamical variable LWP than to the microphysical variable $N_{a}$. The LWP is greatly dependent on the dynamical parameters (i.e., $D$ and SST). This is in agreement with Schwartz et al. (2002), who found a strong dependence of $\tau$ on LWP so that the LWP variability obscured the Twomey effect from the satellite measurements.

\section{Effect of giant sea salt on stratocumulus dynamics}

Sea salt aerosols exhibit a size distribution that is strongly related to the surface wind velocity (e.g., O'Dowd et al. 1997). Because of their size, supermicron sea salt aerosols are more readily activated at low supersaturations than are typical pollution aerosols. It has been shown by adiabatic parcel model simulations (Ghan et al. 1998; O'Dowd et al. 1999) that under high sulfate concentrations, in the competition for available water vapor, coarse mode sea salt particles inhibit the activation of submicrometer sulfate particles sufficiently to reduce the total number of activated particles. In addition, large sea salt particles lead to large cloud drops that facilitate subsequent collision and coalescence and the formation of rain drops. This feature has been applied to the studies of hygroscopic seeding of cumulus clouds (e.g., Johnson 1982; Cooper et al. 1997; Yin et al. 2000; Segal et al. 2004). These numerical seeding experiments revealed that introducing giant $\mathrm{CCN}$ $(a>1 \mu \mathrm{m})$ resulted in a significant potential of rain enhancement for continental (polluted) clouds. However, they found insignificant impact of seeding the maritime (clean) clouds due to already efficient collision and coalescence process in these clouds. This dynamical effect of giant sea salt aerosols on precipitation has lead to the discussion of their impacts on cloud optical properties. The stratocumulus modeling study by Feingold et al. (1999a) indicates that the presence of very few giant sea salt $\mathrm{CCN}$ enhances drizzle production and reduces the cloud LWP; therefore, it can modulate the influence of anthropogenic aerosol considerably. Based on both the Tropical Rainfall Measuring Mission (TRMM) satellite observation of South Asian polluted air transported to the ITCZ over the Indian Ocean and a one-dimensional parcel model, Rosenfeld et al. (2002) also proposed the similar argument that sea salt aerosols can mitigate the anthropogenic aerosol indirect effect because the aerosolinduced precipitation suppression for polluted clouds is lessened in the presence of large sea salt particles.

\section{a. Weakly precipitating stratocumulus clouds}

To investigate the effect of large sea salt particles on stratocumulus properties, we add giant and ultragiant sea salt aerosols to the sulfate aerosols in the simulation (GSALT, Table 1). The giant and ultragiant sea salt data were taken from measurements reported in O'Dowd et al. (1997). The jet (giant) drop mode, $a_{g}=$ $1 \mu \mathrm{m}, \sigma_{g}=2$, and number concentration $=0.80 \mathrm{~cm}^{-3}$, and the spume (ultragiant) drop mode, $a_{g}=6 \mu \mathrm{m}, \sigma_{g}=$ 3 , and number concentration $=3.15 \times 10^{-6} \mathrm{~cm}^{-3}$. These number concentrations are calculated from O'Dowd et al. (1997) assuming a surface (10-m height) wind speed of $4.47 \mathrm{~m} \mathrm{~s}^{-1}$ derived from the sounding profile. Sea salt density and molar mass are taken to be $2.22 \mathrm{~g} \mathrm{~cm}^{-3}$ (d'Almeida et al. 1991) and $58.44 \mathrm{~g} \mathrm{~mol}^{-1}$, respectively. The osmotic coefficient and the number of dissociated ions for two sea salt modes are assumed 1 and 2, respectively.

The condensational growth of a particle, in terms of its radius, is inversely proportional to the radius. There- 

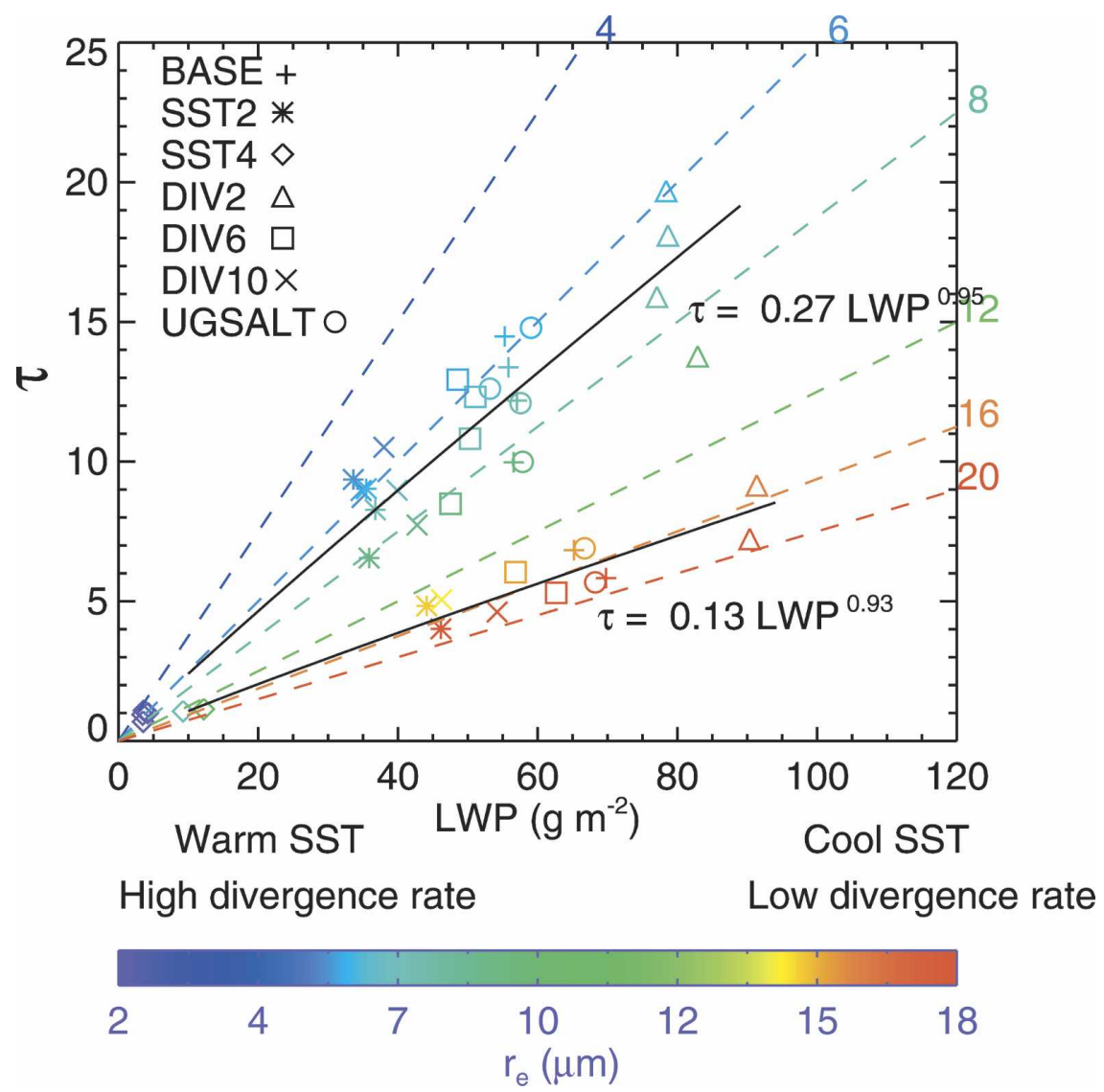

FIG. 9. Cloud optical depth vs cloud LWP for clean and polluted (data points below the constant line of $r_{e}=12 \mu \mathrm{m}$ ) cases for eight simulations. Data points are averaged over the horizontal domain, except that $r_{e}$ is averaged over the upper one-third of the cloud layer; $r_{e}$ is colored by its value given in the color bar. Overlain dashed lines are the theoretical $r_{e}$ defined in Stephens (1978).

fore, the time required for particles to grow to equilibrate with the ambient water vapor concentration rapidly increases with particle size. Small particles can achieve their equilibrium sizes within seconds calculated based on Köhler theory, while large particles such as supermicron sea salt, require much longer time (Mordy 1959). To account for this, we follow the assumption of Feingold et al. (1999a) that giant and ultragiant sea salt aerosol particles, when activated, grow to their $97 \% \mathrm{RH}$ equilibrium sizes, $r_{97}$, which in the model is calculated by the line fitting results of the dry sea salt radius with the corresponding wet radius (Fig. 11), solved iteratively through the Köhler equation at $\mathrm{RH}=97 \%$, that is, $\ln (0.97)=A / r_{97}-\nu a^{3} \rho_{s} M_{w} /$ $M_{s} \rho_{w} r_{97}^{3}$, in a broad size range. The linear regression gives a simple equation, $r_{97}=3.61 a$ ( $a$ is the aerosol dry radius and here it refers to the giant and ultragiant sea salt aerosols). The number and mass of activated sea salt aerosols (where $a \geq a_{\mathrm{cut}, i}$ ) with the wet radius of $r_{97}$ are mapped to the cloud droplet size bins (see Fig. 11 for an example showing the fraction of the number of activated giant and ultragiant sea salt CCNs mapped to the cloud droplet size bins.) Therefore, large drops initially form from the large sea salt particles. Sulfate and sea salt aerosols are activated based on the previously described multimode activation scheme.

The introduction of large sea salt particles inhibits the activation of sulfate particles by reducing maximum cloud supersaturation as a result of the competition for available water vapor. Because the cloud droplets are relatively large and few in a clean cloud, the competition for available water vapor between relatively few sea salt particles and sulfate particles does not greatly reduce the number of cloud droplets formed, as expected for polluted clouds. The clean clouds also readily precipitate, so the addition of a small number of giant sea salt particles does not greatly enhance the precipitation process. Therefore, inclusion of a small amount of giant sea salt $\mathrm{CCN}$ has a negligible effect on cloud properties under clean conditions; however, more 


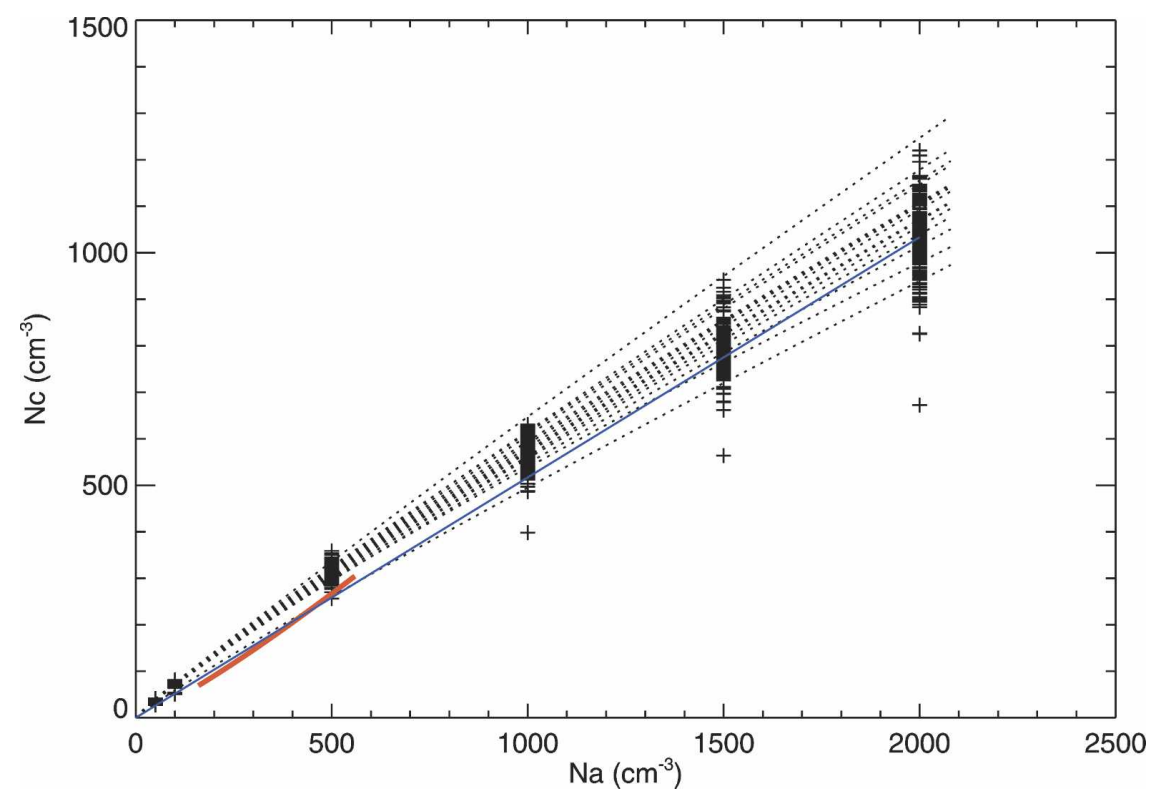

FIG. 10. Regression of $N_{c}$ vs $N_{a}$ at every binned LWP with bin size of $5 \mathrm{~g} \mathrm{~m}^{-2}$ with 5-min sampling frequency (for LWP $\geq 25 \mathrm{~g} \mathrm{~m}^{-2}$, data points are represented by plus) during the final $3 \mathrm{~h}$ (dotted lines). The long solid line is the averaged results of the dotted lines. The short thick line is from DYCOMS-II measurements (Fig. 1 of Twohy et al. 2005).

noticeable impacts are seen at progressively higher sulfate aerosol concentration. Cloud droplet number concentrations are lowered by the presence of a few giant sea salt particles in the polluted cases (Fig. 4a). The effect on $r_{e}$ of larger droplets that result from sea salt can be seen at high $N_{a}$ in Fig. 4b. Large sea salt particles also have the potential to initiate precipitation-sized drops through collision and coalescence, and in their presence, precipitation forms for nondrizzling clouds in the BASE simulation (Fig. $4 \mathrm{c}, N_{a} \geq 500 \mathrm{~cm}^{-3}$ ). The cloud LWP, however, does not show identifiable changes from adding supermicron sea salt because the surface precipitation is too small (Fig. 4d). (The fluctuations in LWP in the presence of sea salt in Fig. $4 \mathrm{~d}$ are comparable to the standard deviation of the data points and should not be considered of significance.) Finally, there is little impact on $\tau$ due to sea salt; in this particular scenario, thereby, giant sea salt particles do not lessen aerosol indirect forcing. The reason is that the BASE simulated case is a weakly drizzling stratocumulus cloud with cloud top around $800 \mathrm{~m}$. [Note that Rosenfeld et al. (2002) considered much stronger cumulus convection with cloud top exceeding $2 \mathrm{~km}$.] For this reason, we now consider a more heavily precipitating case.

\section{b. Heavily precipitating stratocumulus clouds}

The sounding profile in the BASE simulation does not have sufficiently high humidity to produce substan- tial precipitation, even in the presence of the giant sea salt particles or at the low CCN conditions. To fully explore the effect of sea salt, we perform a simulation of a strongly precipitating shallow stratocumulus cloud. The simulation is initialized by the sounding profile (Fig. 12) from Stevens et al. (1998), based on measurements taken from ASTEX. This sounding is more humid than that in Fig. 1. Similar to the case in section 3a,
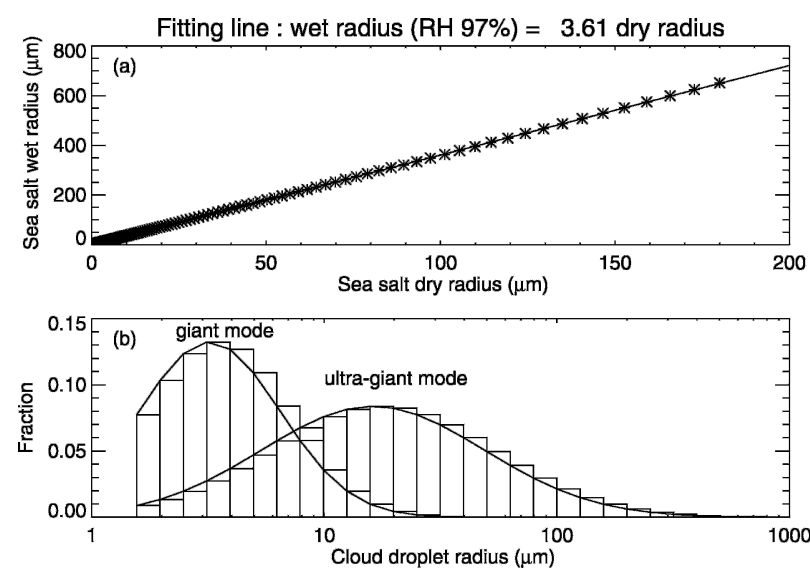

FIG. 11. (a) Linear regression results of the dry sea salt aerosol radius with the corresponding wet radius at $\mathrm{RH}=97 \%, r_{07}$, at 285 $\mathrm{K}$ for 200 size bins in the dry size range of $a_{g}$ (giant) $/ 10 \sigma_{g}$ (giant) $=0.05 \mu \mathrm{m}-10 a_{g}$ (ultragiant) $/ \sigma_{g}$ (ultragiant) $=180 \mu \mathrm{m}$; (b) spectrum of fractions of the number of activated giant and ultragiant sea salt aerosols mapped to the 36 cloud droplet size bins in the model. 

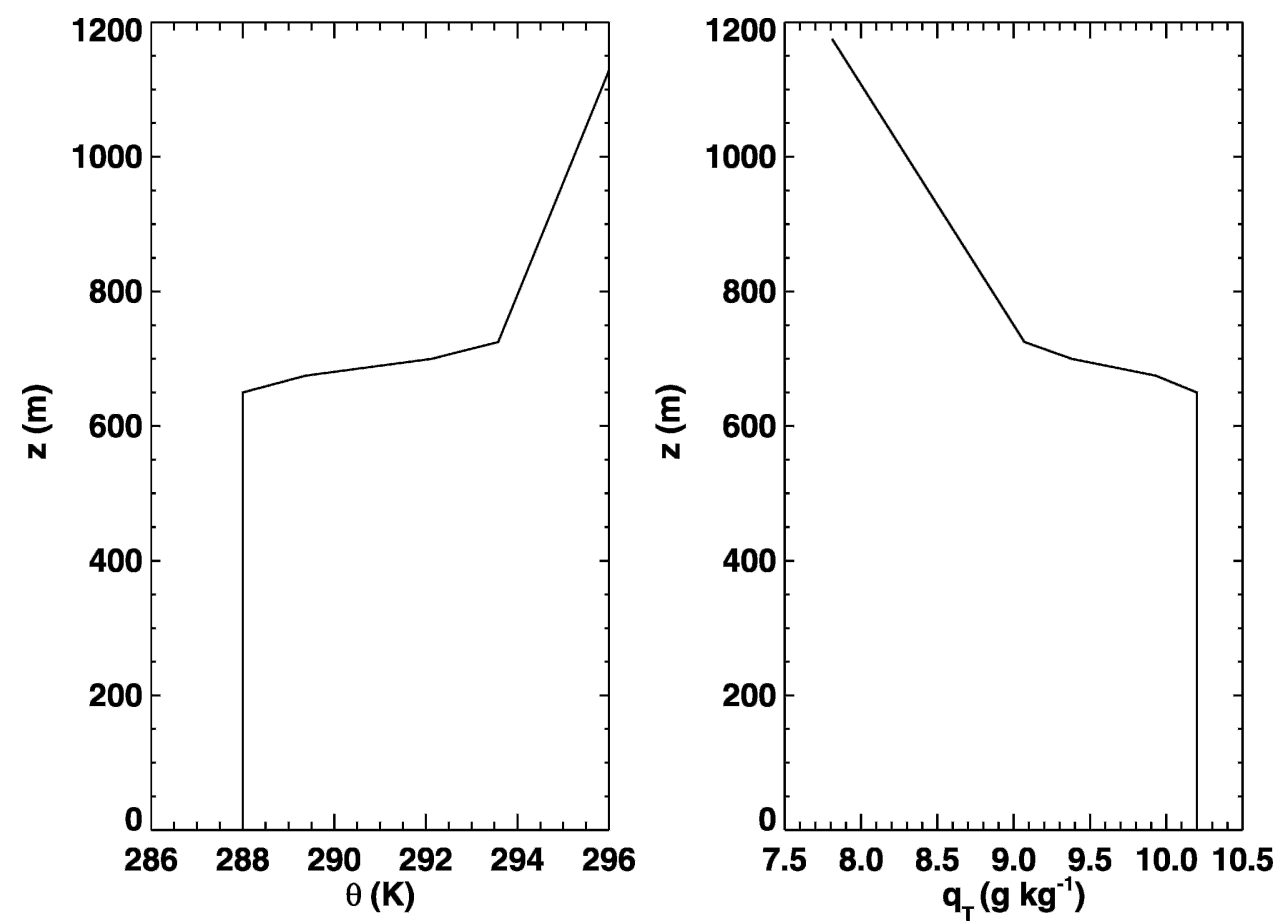

FIG. 12. Initial sounding profile for a heavily precipitating stratocumulus cloud (data from Stevens et al. 1998).

we compare the simulation results from the horizontal domain size of $1.1 \mathrm{~km} \times 1.1 \mathrm{~km}$ and $3.3 \mathrm{~km} \times 3.3 \mathrm{~km}$ (Fig. 13). Again, the cloud optical depth of the large domain is greater than that of the small domain. The figure shows that the trends of $\tau$ versus $N_{a}$ are different in these two domain configurations with the slope for the polluted clouds slightly larger for the large domain. Therefore, the typical $3.3 \mathrm{~km} \times 3.3 \mathrm{~km}$ domain is adopted for the following ASTEX simulations.

We consider three sets of simulations using this sounding profile (Table 1): the first is BASEH simulation in which only sulfate aerosols are present, the second one is UGSALTH in which the two large sea salt modes are added to the sulfate particles, and the third one is GSALTH in which only the jet drop mode sea salt is added to the sulfate as a comparison to UGSALTH. The wind speed at $10 \mathrm{~m}$ calculated from this sounding is $2.12 \mathrm{~m} \mathrm{~s}^{-1}$, giving the sea salt number concentrations of $0.633 \mathrm{~cm}^{-3}$ and $2.17 \times 10^{-6} \mathrm{~cm}^{-3}$ for giant and ultragiant modes, respectively. Before conducting GSALTH and UGSALTH, we have tested the simulation in the $1.1 \mathrm{~km} \times 1.1 \mathrm{~km}$ domain. Results (not shown) show that, when the drizzle process is already quite active under clean conditions, the effect of giant sea salt is negligible and it only has noticeable impacts when $N_{a} \geq 1000 \mathrm{~cm}^{-3}$. Therefore, we only consider sulate aerosol number concentrations above $1000 \mathrm{~cm}^{-3}$, and one extra concentration of $2500 \mathrm{~cm}^{-3}$ is added to exhibit the giant sea salt effect.

Temporal evolution of the simulated cloud droplet number concentration and surface precipitation rate for high pollution is given in Fig. 14. Significant responses on the cloud droplet activation are seen during the first three hours in that cloud droplets numbers are inhibited by the coexistence of the large sea salt aerosols.

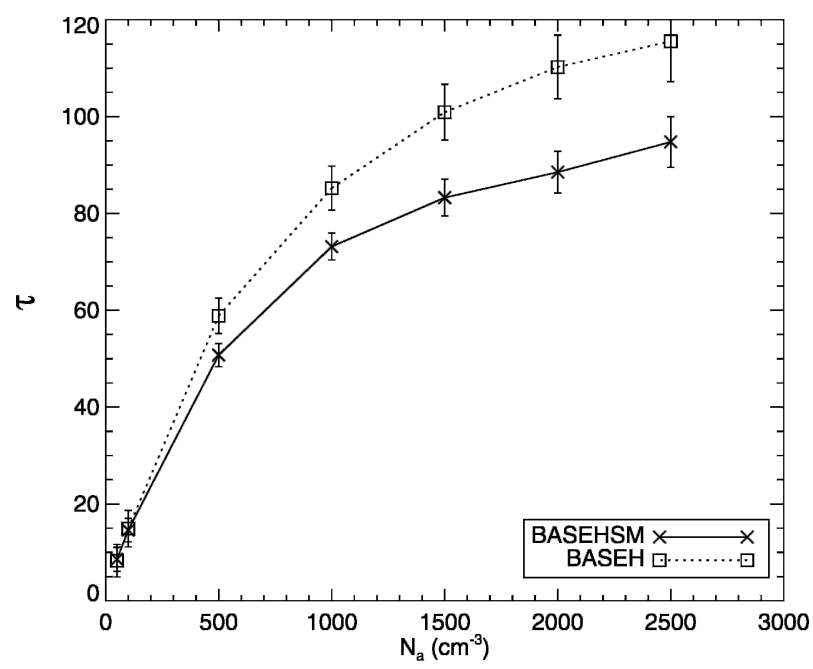

FIG. 13. As in Fig. 2 but for the BASEH run. 

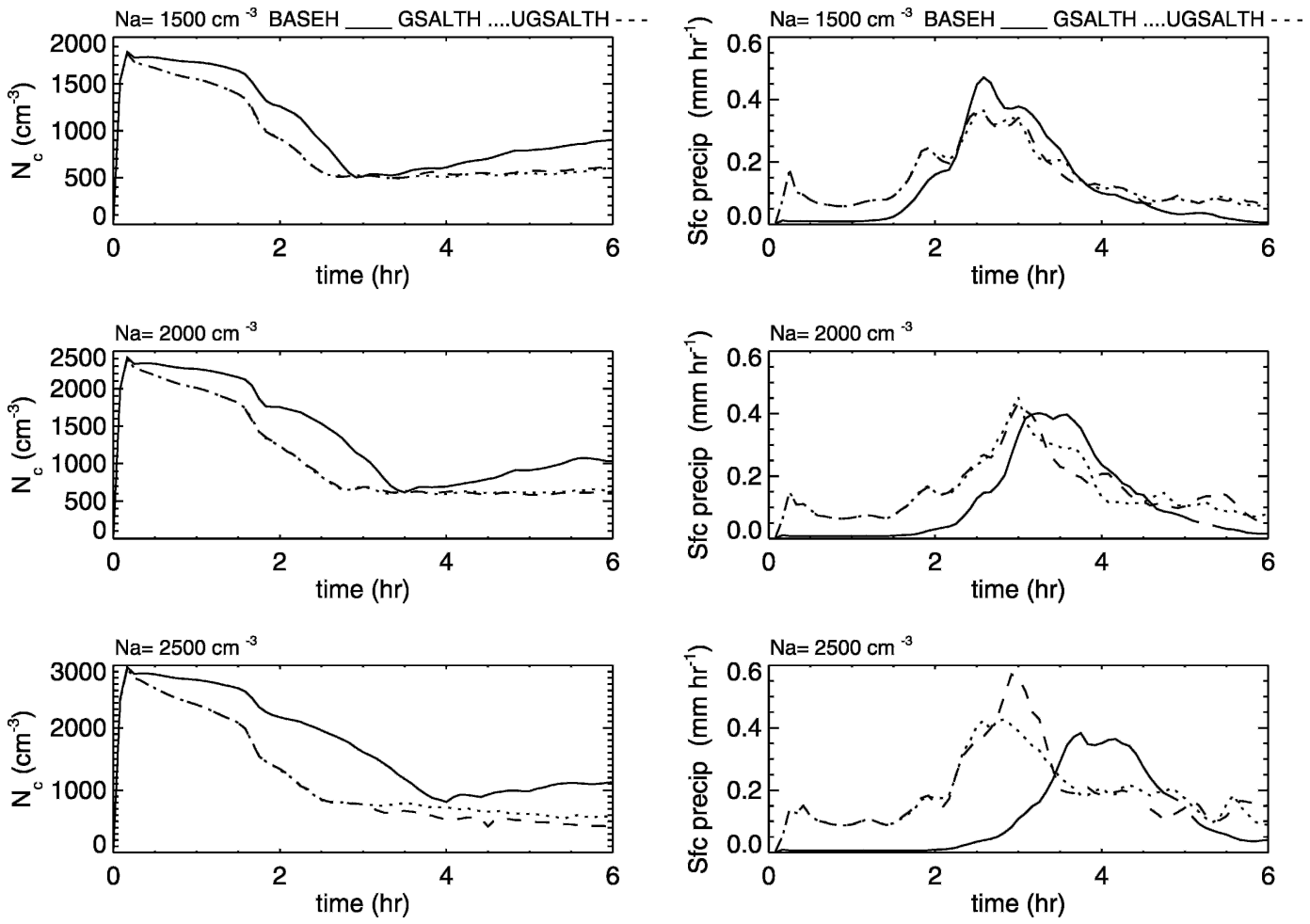

FIG. 14. Temporal evolution of (left) domain-averaged cloud droplet number concentration and (right) surface precipitation rate at high aerosol loadings $\left(N_{a}=1500,2000\right.$, and $\left.2500 \mathrm{~cm}^{-3}\right)$ for BASEH, GSALTH, and UGSALTH.

Early surface precipitation formation due to the addition of the large sea salt is shown. The larger difference of the peak surface precipitation rate (and also accumulated surface precipitation) between the BASEH and GSALTH (or UGSALTH) at the higher sulfate concentration indicates a larger impact of the large sea salt. The comparison of the GSALTH and UGSALTH on several simulated variables shown in Fig. 14 and Fig. 15 suggest that the large sea salt impact is dominated by the giant (jet, $a_{g}=1 \mu \mathrm{m}$ ) sea salt mode rather by the ultragiant (spume, $a_{g}=6 \mu \mathrm{m}$ ) mode, possibly because of the very small concentration of ultragiant mode. This result is in agreement with the conclusion from the 2000-bin spectral cloud parcel model of the hygroscopic seeding study (Segal et al. 2004), which found the optimum seeding particle is around 1.5-2.0 $\mu \mathrm{m}$. In Fig. 16, the horizontally averaged drop number concentration spectrum at $t=5 \mathrm{~h}$ shows a significant reduction of cloud droplet number concentration, especially near cloud base where activation is prominent. This figure also shows that activation of ultragiant sea salt and drop collision and coalescence result in an enhanced drop number concentration in the drizzle size category. These results exhibiting suppression of activation of sulfate cloud droplets in the presence of giant sea salt particles are in essential agreement with cloud parcel simulations by Ghan et al. (1998) and O'Dowd et al. (1999). The averaged cloud droplet effective radius shown in Fig. 15b is increased at large $N_{a}$ in the presence of the giant sea salt aerosols. This increased effective radius significantly enhances the drizzling process (Fig. 15c), and the effect increases with increasing sulfate concentration.

The cloud LWP of BASEH run increases with $N_{a}$ (Fig. 15d) because of the suppression of precipitation for more polluted clouds with smaller cloud droplet sizes, the second indirect effect. Unlike the weakly precipitating stratocumulus in section 5a, the impact of giant sea salt on lowering the cloud LWP is significant for polluted cases. Figure 15e demonstrates that cloud optical depth generally shows a trend similar to that of LWP and the impact of the sea salt increases with higher sulfate concentrations. The percentage change in cloud properties resulting from inclusion of giant sea salt (UGSALTH) relative to the base simulation (BASEH) averaged over the final hour of the simulation for polluted cases is summarized in Table 2. It can be seen that the effect of giant sea salt on polluted clouds increases with particle loading for $N_{a} \geq 1000$ $\mathrm{cm}^{-3}$. Suppression of the cloud LWP and cloud optical depth due to sea salt increases from around 3\% to $77 \%$. In summary, the impact of giant sea salt aerosols on 

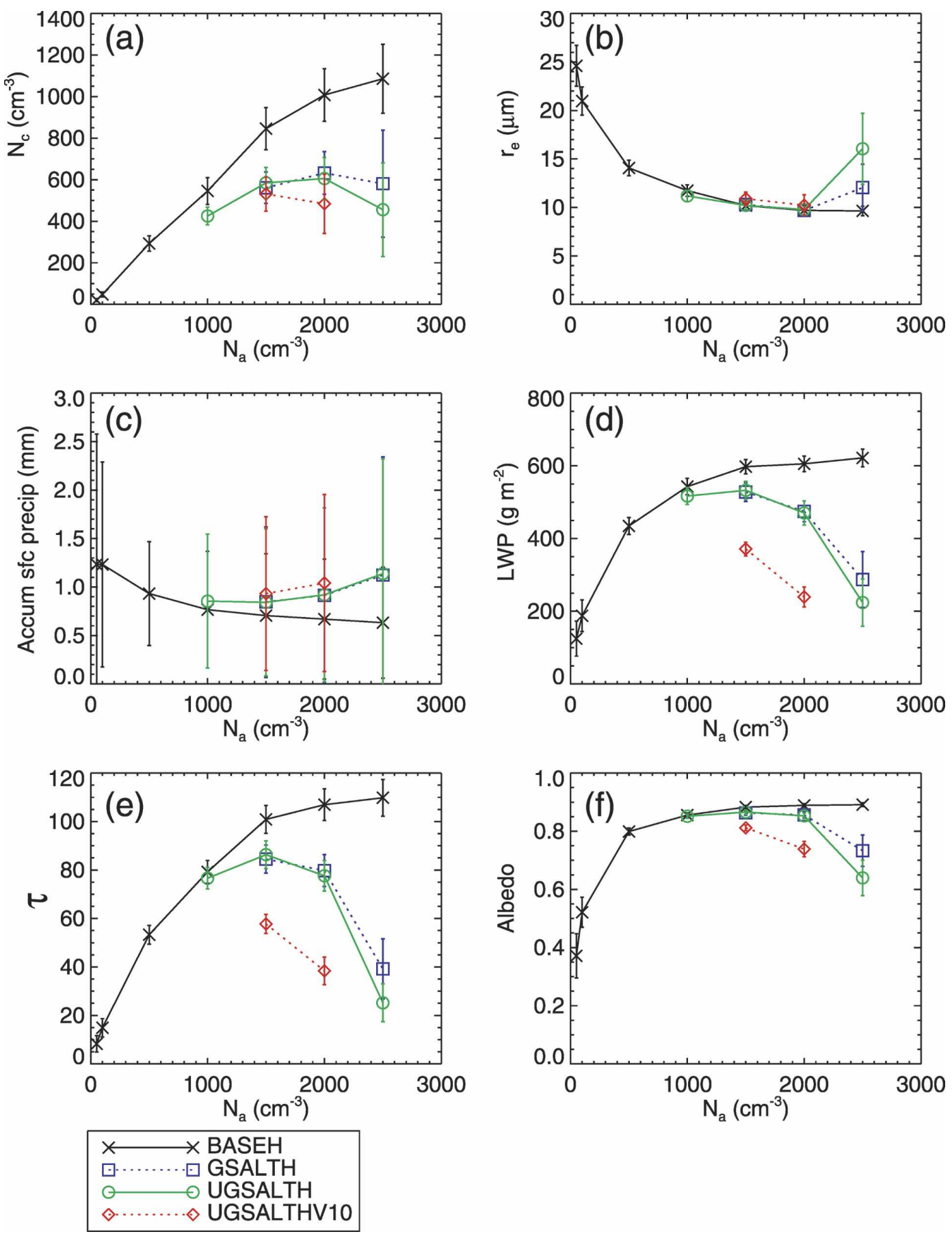

FIG. 15. Simulation results of the ASTEX sounding (Fig. 12) on different sulfate aerosol concentrations as seen on (a) $N_{c}$, (b) $r_{e}$, (c) accumulated surface precipitation, (d) cloud LWP, (e) $\tau$, and (f) cloud albedo. Data are domain averaged during the final hour of the simulation. The accumulated surface precipitation is summed over the 6-h simulations.

cloud optical depth for polluted cases is only evident for a humid and potentially convective atmospheric environment capable of triggering active precipitation.

Finally, in order to assess the effect of higher sea salt concentrations associated with higher wind speed, we increased the initial $v$-component wind speed to 10 $\mathrm{m} \mathrm{s}^{-1}$ (UGSALTHV10, Table 1); the giant sea salt number concentrations calculated based on this wind 


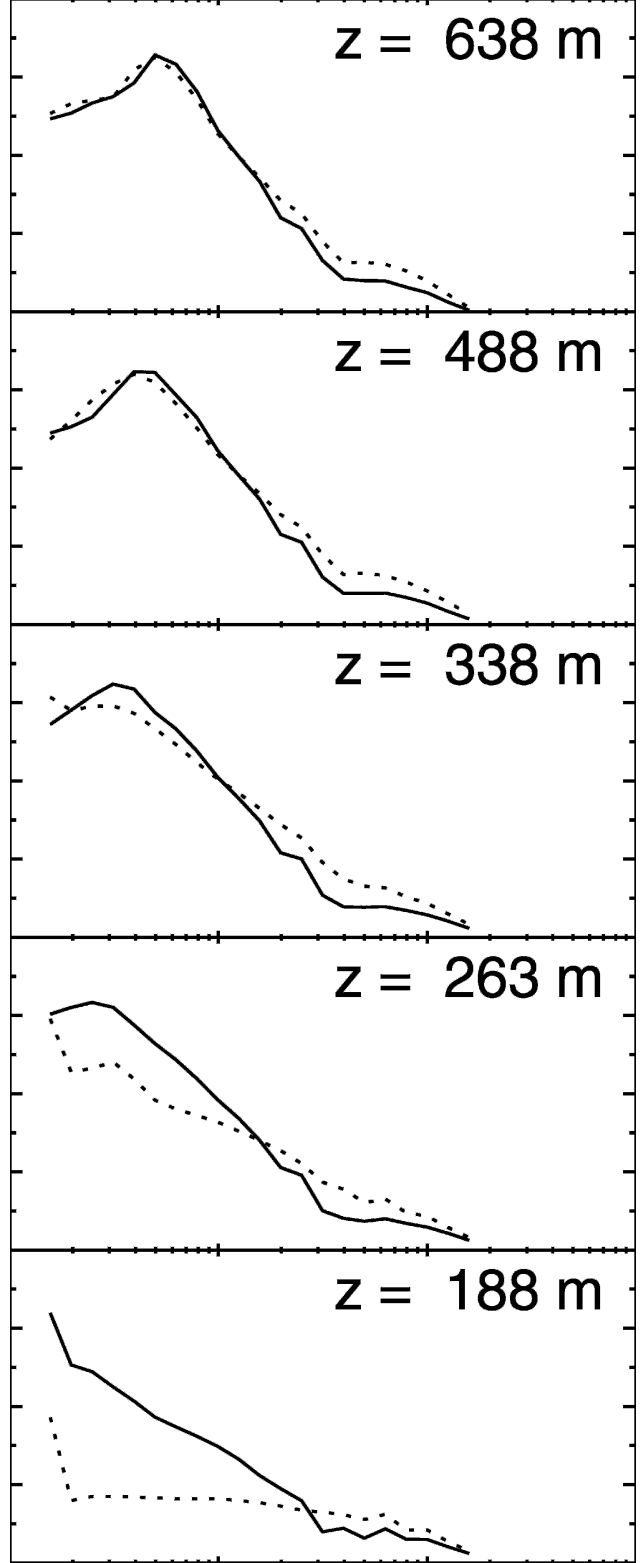

FIG. 16. Layer-averaged drop spectra for $N_{a}=2000 \mathrm{~cm}^{-3}$ at selected heights at $t=5 \mathrm{~h}$. Solid line is BASEH run and dotted line is UGSALTH.

speed are $1.36 \mathrm{~cm}^{-3}$ and $7.6 \times 10^{-6} \mathrm{~cm}^{-3}$ for giant and ultragiant drop modes, respectively. Simulation results for $N_{a}=1500$ and $2000 \mathrm{~cm}^{-3}$ are shown in Fig. 15 and Table 2, indicating that stronger wind shear leads to a more turbulent boundary layer and produces more sea salt aerosol activated. Therefore, the greater sea salt impacts are seen under the stronger wind shear.

\section{c. Aerosol washout}

The heavily precipitating cloud described in the previous subsection could result in a noticeable removal of aerosol number concentration due to the wet scavenging of the aerosol particles with rain drops. We apply the size dependent first-order number washout coefficients from Dana and Hales (1976) to the aerosol number concentration governing equation. The washout coefficients consider Brownian diffusion, interception, and inertial impaction, derived from their Table 3 for the sulfate aerosol lognormal distribution specified in section 3a. The washout coefficient is a function of rizzle size. The aerosol number concentration is now treated as a prognostic scalar, affected by advection, turbulent eddy mixing, and washout. We only perform the simulations for clean clouds $\left(N_{a}=50\right.$ and 100 $\mathrm{cm}^{-3}$ ), named as WASHOUTH (Table 1), owing to prominent drizzling and thereby larger drizzle washout efficiency relative to the polluted clouds. A test of aerosol washout using $N_{a}=2000 \mathrm{~cm}^{-3}$ verified that explicit treatment of washout introduces negligible effects to the simulated polluted cloud properties (not shown). Simulation results (Fig. 17) display that, because of the aerosol washout by drizzle drops, the subsequently activated cloud droplets numbers are reduced, resulting in larger cloud effective radius, enhancement of drizzling, and simultaneous reductions of cloud LWP and optical depth. However, the results also show that the slopes of the LWP $-N_{a}$ (Fig. 17d) and $\tau-N_{a}$ (Fig. 17e) relationships are close to those that do not include the aerosol washout mechanism, suggesting that neglect of this mechanism does not significantly affect the LWP$N_{a}$ and $\tau-N_{a}$ relationships with only sulfate aerosols present.

\section{Daytime conditions}

Although many studies of stratocumulus clouds focus on the nocturnal clouds, the aerosol indirect effect applies to daytime conditions. Therefore we have carried out simulations for the light precipitation case BASE and the heavily precipitating case BASEH with solar radiation, that is, BASESW and BASEHSW, respectively (Table 1). The simulation time spans from local standard time 0900 to 1500 . To conform with our previous analysis procedure, the last three hours and last one hour results for BASESW and BASEHSW are used and shown in Fig. 4 and Fig. 18, respectively. For both cases, the solar heating absorbed by the cloud offsets the cloud-top longwave (LW) cooling, which is the driving force for the turbulent eddies in the MBL. Both the turbulent kinetic energy and $\overline{w^{\prime} w^{\prime}}$ are decreased (not shown). The daytime clouds become thinner with fewer number of activated cloud droplets than the nocturnal clouds as result of weaker updraft. The daytime cloud LWP is decreased mostly due to the shal- 
TABLE 2. Relative change in averaged cloud properties due to introduction of large sea salt aerosols into BASEH simulation. Results are averaged over the last $1 \mathrm{~h}$ of the simulation.

\begin{tabular}{|c|c|c|c|c|c|c|c|c|c|}
\hline \multirow{2}{*}{$\begin{array}{c}N_{a} \\
\left(\mathrm{~cm}^{-3}\right)\end{array}$} & \multicolumn{3}{|c|}{$N_{c}(\%)$} & \multicolumn{3}{|c|}{$r_{e}(\%)$} & \multicolumn{3}{|c|}{ Accumulated surface precipitation (\%) } \\
\hline & UGSALTH & GSALTH & $\overline{\text { UGSALTHV10 }}$ & UGSALTH & GSALTH & $\overline{\text { UGSALTHV10 }}$ & UGSALTH & GSALTH & UGSALTHV10 \\
\hline 1000 & -22.1 & & & -4.7 & & & 11.5 & & \\
\hline 1500 & -30.9 & -33.6 & -48.6 & 0.2 & 1.2 & 4.8 & 19.4 & 20.1 & 40.2 \\
\hline 2000 & -39.9 & -37.3 & -58.0 & 0.9 & -0.1 & 11.2 & 37.5 & 36.8 & 47.2 \\
\hline 2500 & -58.0 & -46.5 & & 66.6 & 25.0 & & 79.9 & 77.6 & \\
\hline \multirow{2}{*}{$\begin{array}{c}N_{a} \\
\left(\mathrm{~cm}^{-3}\right)\end{array}$} & \multicolumn{3}{|c|}{ LWP (\%) } & \multicolumn{3}{|c|}{$\tau(\%)$} & \multicolumn{3}{|c|}{ Albedo (\%) } \\
\hline & UGSALTH & GSALTH & UGSALTHV10 & UGSALTH & GSALTH & UGSALTHV10 & UGSALTH & GSALTH & UGSALTHV10 \\
\hline 1000 & -4.8 & & & -3.3 & & & -0.5 & & \\
\hline 1500 & -10.9 & -11.7 & -28.7 & -14.4 & -16.3 & -36.7 & -1.9 & -2.2 & -6.4 \\
\hline 2000 & -22.3 & -21.6 & -29.6 & -27.4 & -25.4 & -41.1 & -4.1 & -3.7 & -7.3 \\
\hline 2500 & -64.0 & -53.8 & & -77.0 & -64.3 & & -28.2 & -17.7 & \\
\hline
\end{tabular}

lower cloud depth. Consequently, daytime cloud optical depth is smaller than that of the nighttime cloud in response of the smaller LWP. The surface precipitation (not shown) is also decreased during daytime owing to weaker boundary turbulence. For BASESW, the LWP and cloud optical depth show similar trends but smaller magnitude as compared with the results from nocturnal BASE. For BASEHSW, besides the weaker turbulent motion, the stratocumulus is decoupled from the subcloud layer due to the solar heating within the cloud. The daytime decoupled MBL has been observed during the ASTEX field campaign (Ciesielski et al. 2001). The MBL structure shows a thin solid layer of stratocumulus at the top with underlying cumuli (not shown). The decoupled MBL cuts off the moisture transport to the cloud layer and greatly reduces the cloud LWP. However, because of essentially no precipitation, the cloud LWP does not respond to $\mathrm{CCN}$ number variation, which is consistent with the simulation results in Ackerman et al. (2003) and the Monterey Area Ship Track (MAST) observations (Ferek et al. 2000).

To evaluate the effect of cloud dynamics through night on the daytime simulations, we carry out the simulations of the entire diurnal cycle for several selected aerosol number concentrations (BASEHDIU: see Table 1). The diurnal simulation is from 2300 to 1600 LST. Results for early morning (0800-1000), noon (1100-1300), and afternoon (1400-1600) are shown in Fig. 18. Temporal evolutions show that the cloud droplet number concentration, LWP, cloud optical depth, and albedo decreased from nighttime to daytime. The results of afternoon BASEHDIU generally agree with BASEHSW; therefore, neglecting the nighttime cloud dynamics does not produce a significant effect on the daytime simulated variables shown in Fig. 18. Early morning BASEHDIU still exhibits nighttime characteristics such that the trends of the variables versus $N_{a}$ shown in Fig. 18 are similar to those from BASEH.

\section{Implications for the aerosol indirect effect}

Cloud optical depth depends on both $N_{a}$ and LWP. LWP is strongly dependent on external dynamical forcing parameters, such as, SST and large-scale divergence

TABLE 3. Evaluation of aerosol indirect effect of Eq. (15) $\left.\left(\partial \ln \tau / \partial \ln N_{a}\right)\right|_{D, \mathrm{SST}}=\alpha+\left.\beta\left(\partial \ln L \mathrm{WP} / \partial \ln N_{a}\right)\right|_{D, \mathrm{ss} T}$ and the contribution from the first and second aerosol indirect effect. The number in the parentheses denotes the number of data points. Data points are obtained by a 5-min sampling frequency during the last $3 \mathrm{~h}(1 \mathrm{~h})$ for FIRE (ASTEX) drizzling case except for BASEHDIU.

\begin{tabular}{|c|c|c|c|c|c|c|}
\hline \multirow[b]{2}{*}{ Expt } & \multicolumn{2}{|c|}{$\left.\frac{\partial \ln \tau}{\partial \ln N_{a}}\right|_{D, \mathrm{SST}}$} & \multirow[b]{2}{*}{$\alpha$} & \multirow[b]{2}{*}{$\beta$} & \multicolumn{2}{|c|}{$\left.\frac{\partial \operatorname{lnLWP}}{\partial \ln N_{a}}\right|_{D, \mathrm{SST}}$} \\
\hline & Clean & Polluted & & & Clean & Polluted \\
\hline LIGHTDALL & $0.22 \pm 0.07(444)$ & $0.28 \pm 0.05(888)$ & 0.31 & 0.93 & $-0.10 \pm 0.08$ & $-0.03 \pm 0.05$ \\
\hline BASESW & $0.18(74)$ & $0.23(148)$ & 0.29 & 0.79 & -0.14 & -0.08 \\
\hline BASEH & $0.87(26)$ & $0.46(65)$ & 0.22 & 1.10 & 0.59 & 0.22 \\
\hline BASEHDIU (08-10 h) & $0.67(50)$ & $0.48(75)$ & 0.29 & 0.96 & 0.40 & 0.20 \\
\hline BASEHSW & $0.30(26)$ & $0.30(65)$ & 0.29 & 1.10 & 0.01 & 0.01 \\
\hline UGSALTH & & $-1.0(52)$ & 0.21 & 1.55 & & -0.78 \\
\hline
\end{tabular}



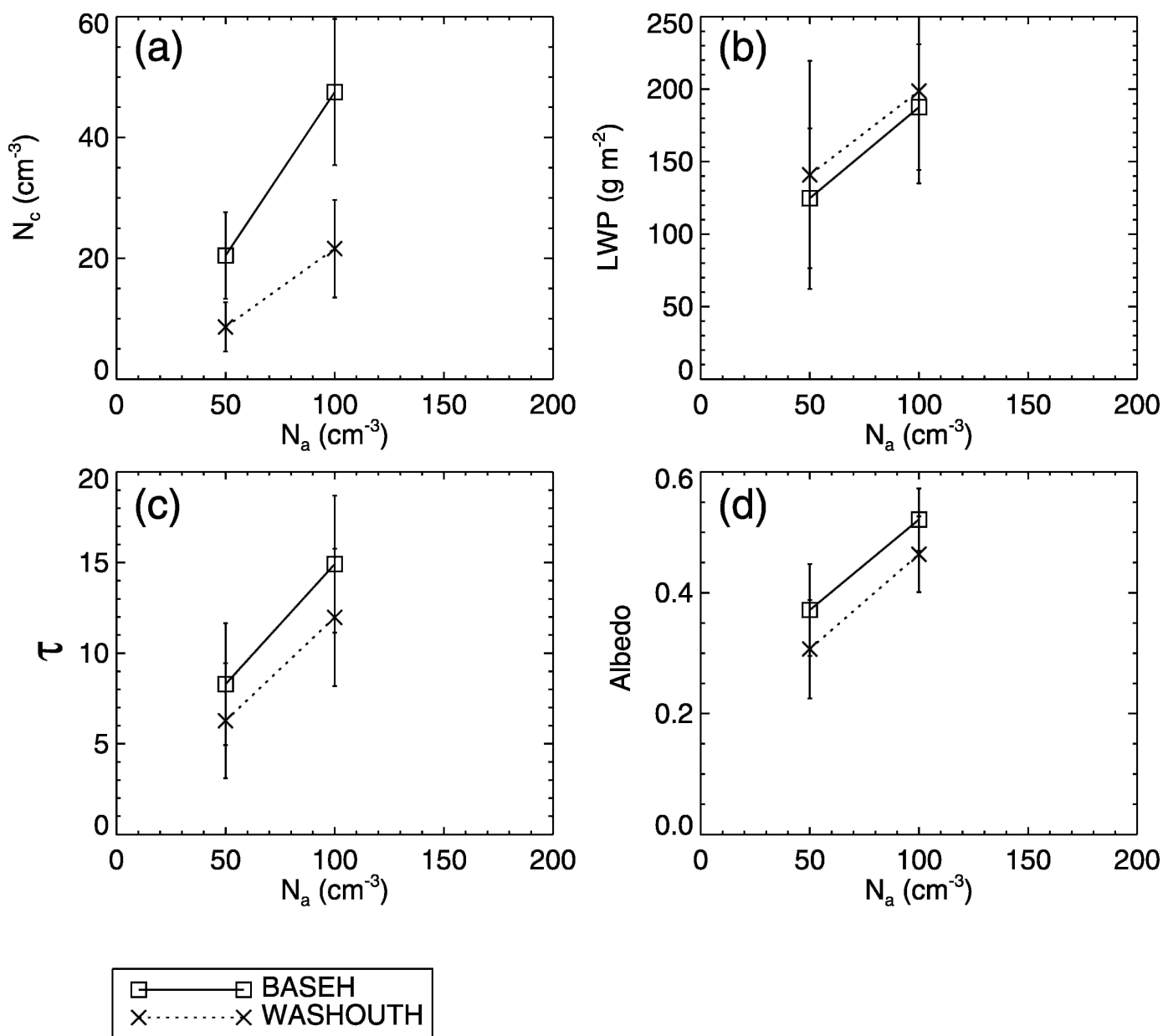

FIG. 17. Similar to Fig. 15 except for the inclusion of aerosol washout by drizzle drops (WASHOUTH).

rate. Through statistical analysis of the simulations shown in section 4 , the cloud optical depth is found to be more sensitive to LWP than to $N_{a}$. It is of interest to evaluate the relative importance of the microphysical and dynamical effects contributing to aerosol indirect forcing. We can write, from Eq. (12),

$$
\left.\frac{\partial \ln \tau}{\partial \ln N_{a}}\right|_{D, \mathrm{SST}}=\alpha+\left.\beta \frac{\partial \operatorname{lnLWP}}{\partial \ln N_{a}}\right|_{D, \mathrm{SST}} .
$$

For the six lightly precipitating experiments of Eq. (12) (i.e., LIGHTDALL), the constants $\alpha=0.31$ and $\beta=$ 0.93 . The term on the left-hand side is the aerosol indirect effect. The first term on the right-hand side $(\alpha)$ represents the Twomey effect. For a spatially uniform cloud with a monodisperse cloud droplet spectrum, $\tau \approx$ $\mathrm{LWP}^{2 / 3} N_{c}^{1 / 3} H$ (Seinfeld and Pandis 1998). Using the empirical relationship of Eq. (13), this idealized cloud gives the same microphysical sensitivity of 0.3 as Eq. (15) for a constant LWP. The second term on the righthand side of Eq. (15),

$$
\left.\beta \frac{\partial \operatorname{lnLWP}}{\partial \ln N_{a}}\right|_{D, \mathrm{SST}},
$$

the second aerosol indirect effect, represents the change of LWP in response to the change in $N_{a}$, that is, the cloud dynamical effect such as the change of cloud LWP (Albrecht 1989) or change of cloud depth (Pincus and Baker 1994) due to aerosol suppression of drizzle. Pincus and Baker (1994) found that the albedo susceptibility is increased by $50 \%-200 \%$ when the dependence of cloud depth on particle number is included.

Table 3 summarizes Eq. (15) for the different experiments of this study. The constants $\alpha$ and $\beta$ for all cases shown in the table are the multiple regression coefficients of cloud optical depth with aerosol number concentration and cloud LWP. The value of

$$
\left.\frac{\partial \operatorname{lnLWP}}{\partial \ln N_{a}}\right|_{D, \mathrm{SST}}
$$



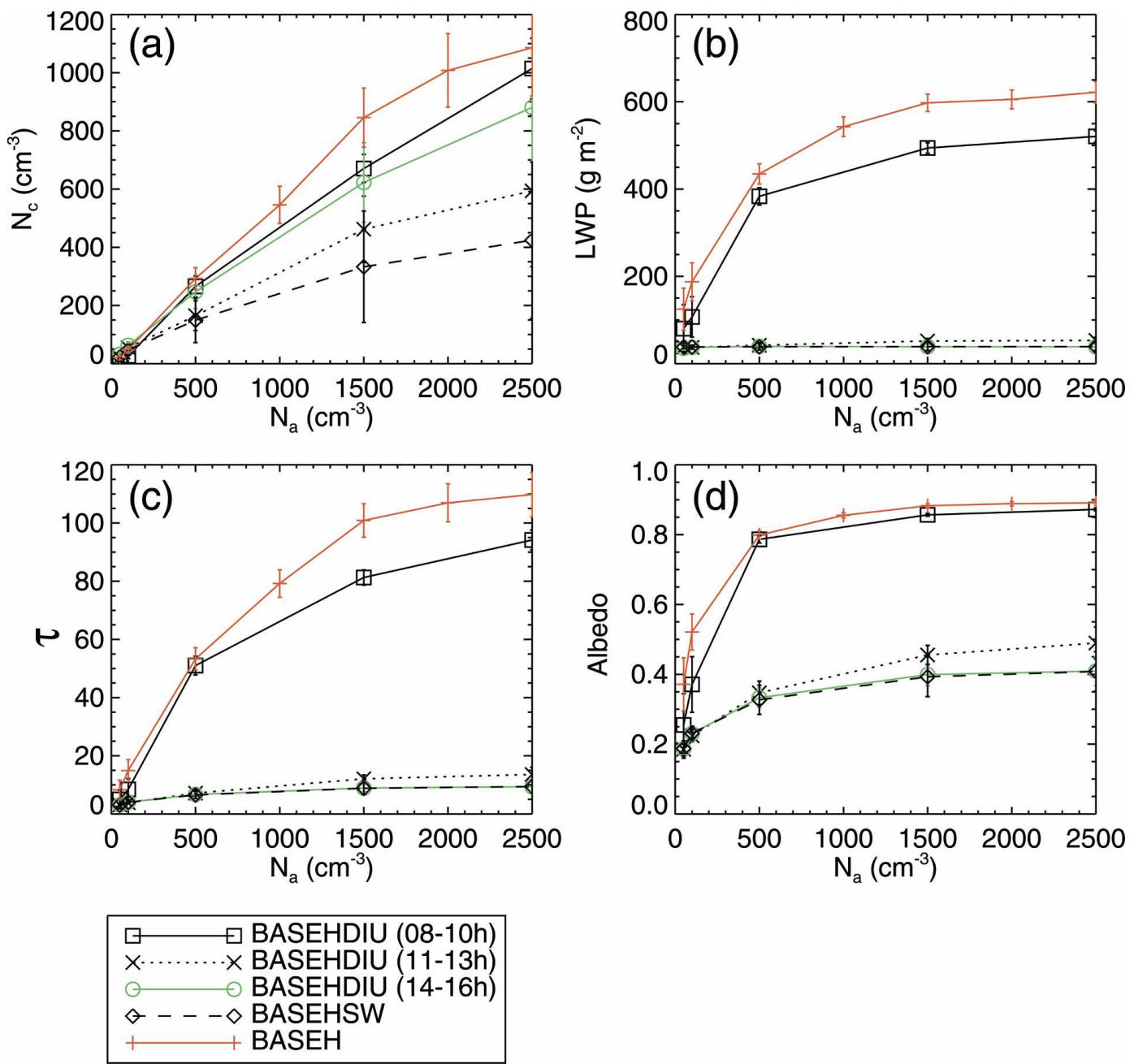

FIG. 18. Simulation results of the ASTEX sounding (Fig. 12) on different sulfate aerosol concentrations as seen on (a) $N_{c}$, (b) LWP, (c) $\tau$, and (d) cloud albedo for the BASEHDIU early morning (0800-1000), noon (1100-1300), and afternoon (1400-1600 LST).

is from the slope of the linear regression of LWP with $N_{a}$ in the natural log space. Results from Table 3 show that clean cases give larger absolute values of

$$
\left.\frac{\partial \operatorname{lnLWP}}{\partial \ln N_{a}}\right|_{D, \mathrm{SST}}
$$

than polluted cases (except for UGSALTH), and hence the clean clouds exhibit a larger second indirect effect than polluted clouds. This is because, for the same meteorological condition, clean clouds more readily produce surface precipitation or cloud drop sedimentation flux than polluted clouds. Heavy surface precipitation can reduce the cloud LWP directly through the drops collision and coalescence process; the more pollution, the smaller droplets, and the less precipitation efficiency. Therefore, this aerosol suppression of drizzle will result in a positive

$$
\left.\beta \frac{\partial \ln L W P}{\partial \ln N_{a}}\right|_{D, \text { SST }},
$$

that is, a positive second indirect effect, and amplifies the overall indirect effect, as suggested from the aerosol suppression of drizzle by Albrecht (1989) and Pincus and Baker (1994). In our simulations, clean clouds that produce high precipitation amounts [BASEH and BASEHDIU (08-10 h)] can be explained by this effect. However, the small negative, or close to zero, aerosol second indirect effect is seen for the clouds that produce little precipitation (LIGHTDALL, BASESW, and BASEHSW). For these cases, drizzle production is inefficient in reducing the cloud LWP. The negative sign for

$$
\left.\frac{\partial \operatorname{lnLWP}}{\partial \ln N_{a}}\right|_{D, \mathrm{SST}}
$$


is likely be due to the slight increase of entrainment drying associated with less efficient cloud droplet sedimentation at high aerosol concentrations. Similar discussions are also seen in the recent work by Ackerman et al. (2004). They further found the condition for the positive sign of

$$
\left.\frac{\partial \operatorname{lnLWP}}{\partial \ln N_{a}}\right|_{D, \mathrm{SST}}
$$

is only when significant surface precipitation for the stratocumulus clouds is greater than $0.1 \mathrm{~mm}$ day $^{-1}$, which is also favored by humid free tropospheric air or very low aerosol concentration.

Daytime (results are averaged during the afternoon) simulations for both the lightly and heavily drizzling cases (BASESW and BASEHSW) show a reduction of the magnitude of the aerosol indirect effect resulting from cloud thinning due to cloud solar absorption. Precipitation is significantly reduced in the daytime simulations, and the aerosol indirect effect is dominated by the Twomey effect. Although the largest values of the aerosol effect occur at nighttime instead of daytime, we have found through the diurnal cycle simulations, the early morning clouds of BASEHDIU shows similar trends of cloud droplet number concentration, LWP, cloud optical depth, and cloud albedo versus aerosol number concentration, and results in comparable aerosol indirect effects with nighttime clouds (BASEH). Therefore, the nighttime results can be applied to early morning cloud (e.g., 0600-1000 LST) when solar heating is small. Results also suggest that, to accurately evaluate the aerosol indirect forcing, the diurnal evolutions of the aerosol indirect effects should be considered. Lastly, the interesting feature of this table shows that the giant sea salt aerosol (UGSALTH) exhibits a negative

$$
\left.\frac{\partial \ln L W P}{\partial \ln N_{a}}\right|_{D, \text { SST }},
$$

which leads to a negative second indirect effect large enough to alter the sign of the overall aerosol effect.

Acknowledgments. This work was supported by Office of Naval Research Grant N-00014-96-1-0119. The authors especially appreciate comments from Dr. Graham Feingold. We also acknowledge computational resources from Caltech Center for Advanced Computing Research.

\section{REFERENCES}

Abdul-Razzak, H., and S. J. Ghan, 2000: A parameterization of aerosol activation. 2. Multiple aerosol types. J. Geophys. Res., 105, 6837-6844. aerosol activation. 1. Single aerosol type. J. Geophys. Res., 103, 6123-6131.

Ackerman, A. S., O. B. Toon, D. E. Stevens, and J. A. Coakley, 2003: Enhancement of cloud cover and suppression of nocturnal drizzle in stratocumulus polluted by haze. Geophys. Res. Lett., 30, 1381, doi:10.1029/2002GL016634.

— M. P. Kirkpatrick, D. E. Stevens, and O. B. Toon, 2004: The impact of humidity above stratiform clouds on indirect aerosol climate forcing. Nature, 432, 1014-1017.

Albrecht, B. A., 1989: Aerosols, cloud microphysics, and fractional cloudiness. Science, 245, 1227-1230.

- C. S. Bretherton, D. Johnson, W. H. Scubert, and A. S. Frisch, 1995: The Atlantic Stratocumulus Transition Experiment-ASTEX. Bull. Amer. Meteor. Soc., 76, 889-904.

Andreae, M., D. Rosenfeld, P. Artaxo, A. Costa, G. Frank, K. Longo, and M. Silva-Dias, 2004: Smoking rain clouds over the Amazon. Science, 303, 1337-1342.

Betts, A., and R. Boers, 1990: A cloudiness transition in a marine boundary layer. J. Atmos. Sci., 47, 1480-1497.

Bohren, C. F., 1980: Multiple scattering of light and some of its observable consequences. Amer. J. Phys., 55, 524-533.

Brenguier, J.-L., H. Pawloska, L. Schüller, R. Preusker, and J. Fischer, 2000: Radiative properties of boundary layer clouds: Droplet effective radius versus number concentration. $J$. Atmos. Sci., 57, 807-821.

,-- , and -2003 : Cloud microphysical and radiative properties for parameterization and satellite monitoring of the indirect effect of aerosols on climate. J. Geophys. Res., 108, 8632, doi:10.1029/2002JD002682.

Bréon, F.-M., D. Tanré, and S. Generoso, 2002: Aerosol effect on cloud droplet size monitored from satellite. Science, 295, 834838.

Chen, C., and W. R. Cotton, 1983: A one-dimensional simulation of the stratocumulus-capped mixed layer. Bound.-Layer Meteor., 25, 289-321.

Chlond, A., and A. Wolkau, 2000: Large-eddy simulation of a nocturnal stratocumulus-topped marine atmospheric boundary layer: An uncertainty analysis. Bound.-Layer Meteor., 95, 31-55.

Ciesielski, P. E., W. H. Schubert, and R. H. Johnson, 1999: Largescale heat and moisture budgets over the ASTEX region. $J$. Atmos. Sci., 56, 3241-3261.

- - , and — , 2001: Diurnal variability of the marine boundary layer during ASTEX. J. Atmos. Sci., 58, 2355-2376.

Coakley, J. A., J. R. Bernstein, and P. A. Durkee, 1987: Effect of ship track effluents on cloud reflectivity. Science, 237, 10201021.

Cooper, W. A., R. T. Bruintjes, and G. K. Mather, 1997: Calculations pertaining to hygroscopic seeding with flares. J. Appl. Meteor., 36, 1449-1469.

d'Almeida, G. A., P. Koepke, and E. P. Shettle, 1991: Atmospheric Aerosols: Global Climatology and Radiative Characteristics. A. Deepak Publishing, 561 pp.

Dana, M. T., and J. M. Hales, 1976: Statistical aspects of the washout of polydisperse aerosols. Atmos. Environ., 10, 45-50.

Deardorff, J. W., 1970: A numerical study of three-dimensional turbulent channel flow at large Reynolds number. J. Fluid Mech., 41, 453-480.

Duynkerke, P. G., and Coauthors, 1999: Intercomparison of three- and one-dimensional model simulations and aircraft observations of stratocumulus. Bound.-Layer Meteor., 92, 453-487. 
Feingold, G., and S. Kreidenweis, 2002: Cloud processing of aerosol as modeled by a large eddy simulation with coupled microphysics and aqueous chemistry. J. Geophys. Res., 107, 4687, doi:10.1029/2002JD002054.

—, B. Stevens, W. Cotton, and R. Walko, 1994: An explicit cloud microphysics/LES model designed to simulate the Twomey effect. Atmos. Res., 33, 207-233.

—, S. Kreidenweis, B. Stevens, and W. Cotton, 1996: Numerical simulations of stratocumulus processing of cloud condensation nuclei through collision-coalescence. J. Geophys. Res., 101, 21 391-21 402.

- R. Boers, B. Stevens, and W. Cotton, 1997: A modeling study of the effect of drizzle on cloud optical depth and susceptibility. J. Geophys. Res., 102, 13 527-13 534.

— , W. R. Cotton, S. M. Kreidenweis, and J. T. Davis, 1999a: The impact of giant cloud condensation nuclei on drizzle formation in stratocumulus: Implications for cloud radiative properties. J. Atmos. Sci., 56, 4100-4117.

— A. S. Frisch, B. Stevens, and W. R. Cotton, 1999b: On the relationship among cloud turbulence, droplet formation and drizzle as viewed by Doppler radar, microwave radiometer and lidar. J. Geophys. Res., 104, 22 195-22 203.

—, W. L. Eberhard, D. E. Veron, and M. Previdi, 2003: First measurements of the Twomey indirect effect using groundbased remote sensors. Geophys. Res. Lett., 30, 1287, doi:10.1029/2002GL016633.

Ferek, R. J., and Coauthors, 2000: Drizzle suppression in ship tracks. J. Atmos. Sci., 57, 2707-2728.

Fitzjarrald, D., and M. Garstang, 1981: Vertical structure of the tropical boundary layer. Mon. Wea. Rev., 109, 1512-1526.

Ghan, S. J., L. R. Leung, R. C. Easter, and H. Abdul-Razzak, 1997: Prediction of cloud droplet number in a general circulation model. J. Geophys. Res., 102, 21 777-21 794.

— - G. Guzman, and H. Abdul-Razzak, 1998: Competition between sea salt and sulfate particles as cloud condensation nuclei. J. Atmos. Sci., 55, 3340-3347.

Han, Q., W. B. Rossow, J. Chou, and R. M. Welch, 1998: Global variation of column droplet concentration in low-level clouds. Geophys. Res. Lett., 25, 1419-1422.

Hansen, J. E., and L. D. Travis, 1974: Light scattering in planetary atmospheres. Space Sci. Rev., 16, 527-610.

Heymsfield, A., and G. McFarquhar, 2001: Microphysics of INDOEX clean and polluted trade cumulus clouds. J. Geophys. Res., 106, 28 653-28 673.

Houghton, J. T., T. Ding, D. J. Griggs, M. Noguer, P. J. van der Linden, X. Dai, K. Maskell, and C. A. Johnson, Eds., 2001: Climate Change 2001: The Scientific Basis. Cambridge University Press, $881 \mathrm{pp}$.

Jiang, H., G. Feingold, W. Cotton, and P. Duynkerke, 2001: Large-eddy simulations of entrainment of cloud condensation nuclei into the Arctic boundary layer: May 18, 1998, FIRE/SHEBA case study. J. Geophys. Res., 106, $15113-$ 15122.

—_ — $\ldots$, and ——, 2002: Simulations of aerosol-clouddynamical feedbacks resulting from entrainment of aerosol into the marine boundary layer during the Atlantic Stratocumulus Transition Experiment. J. Geophys. Res., 107, 4813, doi:10.1029/2001JD001502.

Johnson, D. B., 1982: The role of giant and ultragiant aerosol particles in warm rain initiation. J. Atmos. Sci., 39, 448-460.

Kim, B., S. Schwartz, M. Miller, and Q. Min, 2003: Effective radius of cloud droplets by ground-based remote sensing: Relation- ship to aerosol. J. Geophys. Res., 108, 4740, doi:10.1029/ 2003JD003721.

Koren, I., Y. Kaufman, L. Remer, and J. Martins, 2004: Measurement of the effect of Amazon smoke on inhibition of cloud formation. Science, 303, 1342-1345.

Krueger, S., 1988: Numerical simulation of tropical cumulus clouds and their interaction with the subcloud layer. $J$. Atmos. Sci., 45, 2221-2250.

_ - G. Mclean, and Q. Fu, 1995: Numerical simulation of the stratus-to-cumulus transition in the subtropical marine boundary layer. Part I: Boundary-layer structure. J. Atmos. Sci., 52, 2839-2850.

Menon, S., and Coauthors, 2003: Evaluating aerosol/cloud/ radiation process parameterizations with single-column models and Second Aerosol Characterization Experiment (ACE2) cloudy column observations. J. Geophys. Res., 108, 4762, doi:10.1029/2003JD003902.

Moeng, C., and Coauthors, 1996: Simulation of a stratocumulustopped planetary boundary layer: Intercomparison among different numerical codes. Bull. Amer. Meteor. Soc., 77, 261278

—, P. P. Sullivan, and B. Stevens, 1999: Including radiative effects in an entrainment rate formula for buoyancy-driven PBLs. J. Atmos. Sci., 56, 1031-1049.

Mordy, W., 1959: Computations of the growth by condensation of a population of cloud droplets. Tellus, 11, 16-44.

Nenes, A., and J. Seinfeld, 2003: Parameterization of cloud droplet formation in global climate models. J. Geophys. Res., 108, 4415, doi:10.1029/2002JD002911.

_, R. Charlson, M. Facchini, M. Kulmala, A. Laaksonen, and J. Seinfeld, 2002: Can chemical effects on cloud droplet number rival the first indirect effect? Geophys. Res. Lett., 29, 1848, doi:10.1029/2002GL015295.

O'Dowd, C. D., M. H. Smith, I. E. Consterdine, and J. A. Lowe, 1997: Marine aerosol, sea-salt, and the marine sulphur cycle: A short review. Atmos. Environ., 31, 73-80.

— J. A. Lowe, M. H. Smith, and A. D. Kaye, 1999: The relative importance of non-sea-salt sulphate and sea-salt aerosol to the marine cloud condensation nuclei population: An improved multi-component aerosol-cloud droplet parameterization. Quart. J. Roy. Meteor. Soc., 125, 1295-1313.

Penner, J., X. Dong, and Y. Chen, 2004: Observational evidence of a change in radiative forcing due to the indirect aerosol effect. Nature, 427, 231-234.

Pielke, R. A., and Coauthors, 1992: A comprehensive meteorological modeling system-RAMS. Meteor. Atmos. Phys., 49, 69-91.

Pincus, R., and M. B. Baker, 1994: Effect of precipitation on the albedo susceptibility of marine boundary layer clouds. $\mathrm{Na}$ ture, 372, 250-252.

Pruppacher, H. R., and J. D. Klett, 1997: Microphysics of Clouds and Precipitation. Kluwer Academic, 954 pp.

Randall, D. A., J. A. Coakley Jr., C. W. Fairall, R. A. Kropfli, and D. H. Lenschow, 1984: Outlook for research on subtropical marine stratiform clouds. Bull. Amer. Meteor. Soc., 65, 12901301.

Rosenfeld, D., 1999: TRMM observed first direct evidence of smoke from forest fires inhibiting rainfall. Geophys. Res. Lett., 26, 3105-3108.

- 2000: Suppression of rain and snow by urban and industrial air pollution. Science, 287, 1793-1796.

—, Y. Rudich, and R. Lahav, 2001: Desert dust suppressing 
precipitation: A possible desertification feedback loop. Proc. Natl. Acad. Sci. USA, 98, 5975-5980.

— , R. Lahav, A. Khain, and M. Pinsky, 2002: The role of sea spray in cleansing air pollution over ocean via cloud processes. Science, 297, 1667-1670.

Schubert, W. H., J. S. Wakefield, E. J. Steiner, and S. K. Cox, 1979a: Marine stratocumulus convection. Part I: Governing equations and horizontally homogeneous solutions. J. Atmos. Sci., 36, 1286-1307.

,,--- , and $-1979 \mathrm{~b}$ : Marine stratocumulus convection. Part II: Horizontally inhomogeneous solutions. J. Atmos. Sci., 36, 1308-1324.

Schwartz, S. E., Harshvardhan, and C. M. Benkovitz, 2002: Influence of anthropogenic aerosol on cloud optical depth and albedo shown by satellite measurements and chemical transport modeling. Proc. Natl. Sci. USA, 99, 1784-1789.

Segal, Y., A. Khain, M. Pinsky, and D. Rosenfield, 2004: Effects of hygroscopic seeding on raindrop formation as seen from simulations using a 2000-bin spectral cloud parcel model. Atmos. Res., 71, 3-34.

Seinfeld, J. H., and S. N. Pandis, 1998: Atmospheric Chemistry and Physics: From Air Pollution to Climate Change. John Wiley \& Sons, $1326 \mathrm{pp}$.

Stephens, G. L., 1978: Radiation profiles in extended water clouds. Part II: Parameterization schemes. J. Atmos. Sci., 35, 2123-2132.

Stevens, B., G. Feingold, W. Cotton, and R. Walko, 1996a: Elements of the microphysical structure of numerically simulated nonprecipitating stratocumulus. J. Atmos. Sci., 53, 9801006.

— - R. L. Walko, and W. R. Cotton, 1996b: The spurious production of cloud-edge supersaturations by Eulerian models. Mon. Wea. Rev., 124, 1034-1041.

— - W. R. Cotton, G. Feingold, and C.-H. Moeng, 1998: Largeeddy simulations of strongly precipitating, shallow, stratocumulus-topped boundary layer. J. Atmos. Sci., 55, 3616-3638.

Tripoli, G. J., and W. R. Cotton, 1981: The use of ice-liquid water potential temperature as a thermodynamic variable in deep atmospheric models. Mon. Wea. Rev., 109, 1094-1102.

Twohy, C. H., M. D. Petters, J. R. Snider, B. Stevens, W. Tahnk, M. Wetzel, L. Russell, and F. Burnet, 2005: Evaluation of the aerosol indirect effect in marine stratocumulus clouds: droplet number, size, liquid water path and radiative impact. $J$. Geophys. Res., in press.

Twomey, S., 1977: The influence of pollution on the shortwave albedo of clouds. J. Atmos. Sci., 34, 1149-1152.

Tzivion, S., G. Feingold, and Z. Levin, 1987: An efficient numerical solution to the stochastic collection equation. J. Atmos. Sci., 44, 3139-3149.

- - , and — 1989: The evolution of raindrop spectra. Part II: Collisional collection breakup and evaporation in a rainshaft. J. Atmos. Sci., 46, 3312-3327.

Von der Emde, K., and U. Wacker, 1993: Comments on the relationship between aerosol spectra, equilibrium drop size spectra, and CCN spectra. Beitr. Phys. Atmos., 66, 157-162.

Wakefield, J. S., and W. H. Schubert, 1981: Mixed-layer mode simulations of eastern North Pacific stratocumulus. Mon. Wea. Rev., 109, 1952-1968.

Walko, R. L., W. R. Cotton, M. P. Meyers, and J. Y. Harrington, 1995: New RAMS cloud microphysics parameterization. Part I: The single-moment scheme. Atmos. Res., 38, 29-62.

Warren, S. G., C. J. Hahn, J. London, R. M. Chervine, and R. L. Jenne, 1986: Global distribution of total cloud cover and cloud type amounts over ocean. NCAR/TN-317+STR, NCAR Tech. Note, 29 pp.

Wyant, M. C., C. S. Bretherton, H. A. Rand, and D. E. Stevens, 1997: Numerical simulations and a conceptual model of the stratocumulus to trade cumulus transition. J. Atmos. Sci., 54, 168-192.

Yin, Y., Z. Levin, T. G. Reisin, and S. Tzivion, 2000: The effects of giant cloud condensation nuclei on the development of precipitation in convective clouds-A numerical study. Atmos. Res., 53, 91-116.

Yum, S. S., and J. G. Hudson, 2002: Maritime/continental microphysical contrasts in stratus. Tellus, 54B, 61-73. 